\title{
A Persian Perspective on Grammaticalization of Future Marking
}

\author{
Mostafa Rahimi Rad \\ PhD student of Allameh Tabatabai'e University, Tehran, Iran \\ Email : mostafa60rahimi@gmail.com
}

\begin{abstract}
:
Temporal references have been the subject of many studies around the world. Futurity is specially an elusive concept really difficult to perceive and describe. The present study tries to launch an investigation regarding the variability of future tense in Farsi. 130 sentences extracted from 8 interviews have been explored along with age, gender, presence or absence of temporal adverbial and animacy of the subject. 5 possible variabilities for expressing futurity are considered in the present study. Future time is especially difficult to perceive and in fact it might not occur. This forces us when it comes to the modality in which statements about the future may be interpreted. Not only do we just talk about those future events which are planned, but also that is the only (natural) modality that we can ascribe to those events. Following Fleischman (1982) and Comrie (1985), we suggest that the notion of future tense or futurity marking is a second class function, and the means available to futurity marking are typically borrowed from other constructions in the language However, before a further discussion of the circumstances giving rise to the idea, as well as some facts that seem to follow from this constraint on modality, we would like to give a brief sketch of some ways that futurity is expressed in different languages.

Keywords :

paraphrastic constructions; tenseless future; future variation with age; future variation with animacy of subject; temporal adverb; Future tense in Farsi; finite auxiliary and a finite lexical verb.
\end{abstract}

\section{Introduction}

Directly perceiving Time is impossible. The effects of its passage on the world are obvious, but there is no particular "time-sensing" organ analogous to human light-sensing organs (our eyes). Thus, in some sense our perception of time is similar to our perception of motion (as we also lack a particular "motion-sensing" organ); they are secondary perceptual and cognitive functions.

Many indo-European languages have paraphrastic constructions mark futurity. In some languages, the "Future" auxiliary can also stand on its own as a main verb of a clause; yet, in other languages, it cannot. English actually has both types of future auxiliary. Typically, English uses "will" plus a bare verb to indicate future tense. In modern English, "will" cannot stand on its own as a main verb. However, English also uses the progressive form of go (going) plus an infinitival verb to mark future (often shortened gonna V.). Go, of course, can stand on its own. German uses warden ("become") plus an infinitival verb to mark futrue1. Unlike English "will" (ye similar to English go), warden can also be used by itself as a main verb with the meaning "become"; Im fruhling warden die baume grun "In spring the trees become green." However, despite having this construction at their disposal, German speakers tend to use a present tense verb with a time adverbial to express futurity. As Comrie (1985) notes:

"The languages [German and Finnish] "do" also have specific constructions with exclusively future time reference, e.g. German 'ich werde gehen', ... but such constructions are normally only used where there would otherwise be danger of misunderstanding” (pp.44-45)

Next, we look at French language. In French actually, there is a future tense affix on the verb. Still, French does have a parphrastic which uses the verb aller ("go") plus an infinitival verb. 
There is also the present tense with time adverbial construction, more frequently than in English and more on a par with German (price 1993).

Finally, we turn to serbo-croatian. Future tense is typically expressed by using a clitic formed from the verb hetti "want". Its behavior is interesting, because of the requirement in serbo-croation that clitics immediately follow the first word in the sentence. While this is not directly relevant to the issue of tense, it is important to note that marking for future tense follows the idiosyncrasies of the individual language, and not any more universal principle ruling the grammaticalization of tense. Serbo-croatian also has paraphrastic with the auxiliary biti that can express future, as well as the use of an explicit time adverbial with present tense.

\section{Review of Related Literature}

Researches on temporal references generally and future tense specifically have been carried out by many researchers in the past. Some researchers have attempted to compare the same tense or mood in two or more related languages. Some others have given descriptive accounts of particular languages without comparing or contrasting them with any other languages.

In a study by Olga Mis oska Tomic, the syntax of the Bakjan Slavic future tense was investigated. The structure of the Balkan Slavic future tenses, with a particular reference to the future tenses with modal clitics and finite verbs was discussed in the study. It is shown that all the Balkan Slavic future tenses have developed from restructuring configurations in which subjunctive constructions appear in complement positions of from of the Old Slavic verb xote ti will/want'.

The development has gone through three stages, though not all Balkan Slavic languages have gone through all of them. In the first stage, represented in contemporary Serbo-Croatian, we have finite modal clitics plus infinitives or subjunctive constructions. In the second stage, which is to some extent represented in the south-eastern Serbian dialects, non-finite modal clitics are followed by subjunctive constructions. In the third stage, represented in Macedonian and Bulgarian, non-finite modal clitics are followed by finite verbs. In contemporary Serbo-Croatian, the future tense is constructed by finite modal clitics plus infinitive or subjunctive constructions. The Serbo-Croatian future tense with subjunctive constructions is a mono-clausal raising configuration with a finite auxiliary and a finite lexical verb. Like the Macedonian and Bulgarian future tenses, it has evolved from a restructuring configuration with two finite lexical verbs, though the evolution of the Macedonian and Bulgarian future tenses has passed through three stages. In the first stage, the Macedonian and Bulgarian future tenses had a structure such as the one in the Serbo-Croatian future tense; in the second stage, they had another intermediate structure-the one witnessed in the contemporary south-eastern Serbian dialects, in which a nonfinite modal clitic is followed by a subjunctive construction; in the third stage, the non-finite modal clitics came to be followed by finite verbs. The change from finite to non-finite modal clitics relates to the loss of the subjunctive mood complementizer: when the $j$-features of the modal clitics disappeared and T/AgrSP reappeared to the left of the lexical verb, the subjunctive mood complementizer became superfluous.

In another research, jo-wing lin explored the selective restrictions of tenses and temporal reference of Chinese bare sentences. He discussed temporal reference of Chinese bare sentences 
without any time adverb or tense-like marker. They argued that temporal reference of such sentences can be resolved by selective restrictions of two empty tenses, i.e., covert present tense and covert past tense. They showed that while covert present tense must select a homogeneous situation as its complement, covert past tense must select heterogeneous situation as its complements. They also argued that covert tense must be distinguished from empty tenses that agree with time adverbs, because the latter do not have selective restrictions.

The future tense of Spanish has also been investigated by some researchers. Christopher G. Lyons contends that it has been suggested that languages show a tendency to alternate between synthetic and analytic construction, synthetic forms being replaced by analytic ones, and these then resynthesizing. The first stage in this sequence is exemplified by many developments in early romance, and it is not discussed here. The second stage appears in the resynthesization of the early romance analytic future tense from in Hispano-Romance (as well as in other Romance languages). This process can be related to many regular changes in early Spanish, but part of it, the reduction of the auxiliary habeo, is not well understood, and is examined in detail. All the factors involved in the resynthesization of the analytic future appear to be phonological, and the development seems to be the result of changes specific to Spanish; it cannot therefore be attributed to a universal trend, though it may be that analytic constructions exhibiting the word order found in this one are particularly susceptible to synthesization through sound change.

English tense including future tense has also intrigued many researchers. Anoop sarker in an article called" the conflict between future tense and modality: the case of will in English" asserts that there have been different views in the literature on what the semantics of "will" should constitute. Some consider "will" to be homonymous between a modal and a periphrastic future tense, while some deny that it is a future tense, indicating that its futurity is derived from its modality. In his paper, sarker reviews the evidence for both views and draws a conclusion based on an empirical comparison.

Any consideration of future forms in English will at once come across the vexed question of whether English possesses such a thing as a "future tense". It is questionable whether English possesses such a structure; as comrie (1990:4) points out, "most European languages have a clear grammatical distinction between past and non-past ... but either no grammatical distinction or a much less clear grammatical distinction between future and non-future. "This may well be because "expressions of future time derive diachronically from modal expressions, e.g. of desiderativity such as the English will" (op.cit.45)

This simple present or "tenseless future" is usually associated with fixed schedules, as in the train leaves at five-thirty. However, this does not seem to be a prerequisite for the use of this form, as shown be Dowty's (1979:160) example:

"Oh, number five wins the competition. His performance was unquestionably better than the others".

The crucial feature of this futurate seems to be that "the outcome of the matter has already been decided" (ibid). we might add here "not by the subject", since the only cases where actions originally initiated by the subject take this form are sentences such as I leave tomorrow where although the subject may have initiated a chain of events (by booking a place on a tour, for example) it is now seen as outside their control. This parallels Wecker's (1976) view that present progressive futurate indicates a human agent; while in the simple present the agent is an event. 
It is sometimes suggested that the simple present futurate implies certainty on the part of the speakers. While this may normally be the case, it is not necessarily so (Dowty, 1979:160-161). On some rail networks, the statement the train leaves at five-thirty may be more a matter of faith than certainty; the train will leave at five-thirty may actually inspire more confidence. Without delving into "possible worlds" and international logic, the best explanation seems to be that this form carries a sense of in the normal course of events or ceteris paribus.

The use of the present progressive seems bound to general consideration of progressive aspect. Perhaps the most elegant way of describing this is found in Hofmann (1993:127-129), following Reichenbach (1947). If an event $\mathrm{E}$ has a beginning $\mathrm{B}$ and a finish $\mathrm{F}$, then a predicate using the progressive would normally imply: $\mathrm{B}<\mathrm{R}$ and $\mathrm{F}>\mathrm{R}$, where $\mathrm{R}$ is the time referred to, and the symbols <and> mean "before" and "after" respectively. If $\mathrm{R}=\mathrm{S}$ (the time of speaking), then we use the present progressive (for a more formal semantic view of the progressive, and problems arising from this type of analysis, see Dowty (1979), Saurer (1984) and Ogihara (1990)). This explains the choice of present progressive for actions which are actually taking place at the time of speaking (I am writing an essay now) but leaves the question of why we would use this form for actions in the future. Hofmann explains this by saying that an action in the past sets in motion an event in the future, bringing forward the beginning of that event. Dowty (1979:154) although woring from a different analysis, takes a similar view of "a psychological tendency of humans to extend the temporal 'duration' of an accomplishment ... backward in time to include the preparations for the accomplishment proper."

In Farsi we can also find some works on tenses. Ina study done by Ahmad Reza Lotfi tense, IP, and parametric variations are investigated. This study represents an attempt to explore tense in terms of some temporal features [+/-past, +/-present, +/-future] in relation to TS (temporal standpoint), i.e. where the speaker stands on the time continuum towards which the speaker's / listener's

\section{Methodology}

Future tense in Farsi

The expression of future temporal reference in Farsi is one of the controversial issues of the grammar of Farsi. The speakers of Farsi use various structures and different tense to talk about a future activity. A speaker may use present tense to talk about his future activity. Surprisingly, the speakers of Farsi sometimes use past tense to talk about future. Now look at some variants of the future temporal reference.

Exp1: Che mikuni?

Shahnameh mikhanam

Exp2: Farda be park miayee?

Shayad biayam

Exp3: Hafteye dige be Shiraz miravi?

Ghasd daram beram
What are you doing?

I'm reading Shahnameh.

Do you come to park tomorrow?

I want to go.

Do you go to Shiraz next week?

I want to go.

Exp4: Dar moddate taatilat kar mikoni? What are you doing during the vacation?

Khodam ra baraye konkur amadeh khaham kard.

(I will prepare myself for university entrance exam)

Exp5: Kharid rafti?

Raftam

Did you go shopping?

I did. 
Most of these tenses which were used to indicate a future activity are also used to talk about present. Future verb in Farsi defined to be made by the verb KHASTAN. The future tense conjugation of the verb is shown in Table 1.

Table 1. The Future Conjugation of Raftan

\begin{tabular}{|l|l|l|}
\hline PERSIAN & FARSI FUTURE & ENGLISH FUTURE \\
\hline $1^{\text {st }}$ person $($ sing) & Kaham raft & I will go \\
\hline $2^{\text {nd }}$ person $(\operatorname{sing})$ & Kahi raft & You will go \\
\hline $3^{\text {rd }}$ person $($ sing) & Khahad raft & He/ she will go \\
\hline $1^{\text {st }}$ person $(\mathrm{pl})$ & Kahim raft & We will go \\
\hline $2^{\text {nd }}$ person $(\mathrm{pl})$ & Khahid raft & You will go \\
\hline $3^{\text {rd }}$ person $(\mathrm{pl})$ & Khahand raft & They will go \\
\hline
\end{tabular}

The above mentioned future verb is used to talk about an activity whose occurrence is definite in the future. In the examples the person is determinedly going to prepare himself for the entrance exam. In the present study, the researchers are going to focus on the frequency of occurrences of this future verb along with other variants of future temporal references. It seems that in the standard dialect of Farsi speakers in Iran- the study assumes to be the dialect of Tehrani speakers of Farsi- there is not so much references to the future verb to talk about future activities or intentions. So, it is founded as worthwhile to launch an investigation in this regard.

\section{Discussion}

\subsection{Factor Groups}

Variability in reference to future time is hypothesized to be influenced by several factors. Most of these variability's rely on the speakers' intentions or attitudes towards the realization of future activity. Each researcher can consider several and different factors which he supposes to have effects on the selection of one of those variabilities. We also coded some factors and tried to explore the variability of our dependent variable on those factors. Factors are listed:

1. Gender ( $\mathrm{m}=$ male, $\mathrm{f}=$ female)

2. Age $(\mathrm{O}=$ old $>40)$. $\mathrm{Y}=$ young $[<40])$

3. Animacy of subjects ( $\mathrm{a}=$ animate, $\mathrm{u}=$ inanimate)

4. Temporal adverbial ( $+=$ with adverb, $-=$ without adverb)

5. The interviewees $(1,2,3,4,5,6,7,8$ stand for eight participants)

6. The interviewers ( $c=$ the first interviewer, $\mathrm{d}=$ the second interviewer)

Our first claim is to test whether these claims hold up against actual usage. Pondering, about variabilities in the use of future temporal reference in Farsi, as it was exemplified at the beginning, we considered five variabilities in the use regarding the first five examples we mentioned in the article:

1: $\mathrm{W}=(\exp 4)$ Khaham Raft

$2: \mathrm{S}=(\exp 2)$ present tense for indicating futurity

$3: \mathrm{b}=(\exp 3)$ shows an intention or a decision for the future, not a definite decision

$4: \mathrm{e}=(\exp 2)$ the use of words like bayad $=$ should or shayad $=$ may to show intention

5: $\mathrm{t}=$ the use of present perfect for future

Exp: Nasle baad fekrha fagh kadeh-and (next generation tinking has changed)

The future verb is defined, as it was explained before, as number one, with verb khastan. We hypothesized that in standard dialect of Farsi there is not so many resources to this variability to talk about future. Our objective is to test how much do our hypotheses hold true. 


\subsection{Result and interpretation}

We are now going to discuss and interpret the findings of the study based on the factors we considered to have effects on vaiabilities of future. Table 2 categorizes our interviews based on their gender and shows the number and percentage of each variability that subjects used.

\section{Results and interpretation}

Female

female

\begin{tabular}{|lccccccccr|}
\hline \multicolumn{10}{c}{ group1 group2 group3 group4 group5 group6 group7 group8 sum group } \\
$\mathrm{s}$ & 13 & 0 & 4 & 0 & 0 & 12 & 6 & 0 & 35 \\
$\mathrm{e}$ & 2 & 0 & 0 & 0 & 0 & 2 & 5 & 0 & 9 \\
$\mathrm{~b}$ & 1 & 0 & 8 & 0 & 0 & 1 & 1 & 0 & 11 \\
$\mathrm{w}$ & 0 & 0 & 1 & 0 & 0 & 0 & 4 & 0 & 5 \\
$\mathrm{t}$ & 0 & 0 & 0 & 0 & 0 & 0 & 0 & 0 & 0 \\
sum & 16 & 0 & 13 & 0 & 0 & 15 & 16 & 0 & 60 \\
\hline
\end{tabular}

percentage of female

\begin{tabular}{|lrrrrrrrr|r|}
\hline \multicolumn{10}{c}{ group1 group2 group3 group4 group5 group6 group7 group8 sum group } \\
$\mathrm{s}$ & 81.25 & 0 & 30.77 & 0 & 0 & 80 & 37.5 & 0 & 58.33333333 \\
$\mathrm{e}$ & 12.5 & 0 & 0 & 0 & 0 & 13.33 & 31.25 & 0 & 15 \\
$\mathrm{~b}$ & 6.25 & 0 & 61.54 & 0 & 0 & 6.667 & 6.25 & 0 & 18.33333333 \\
$\mathrm{w}$ & 0 & 0 & 7.692 & 0 & 0 & 0 & 25 & 0 & 8.333333333 \\
$\mathrm{t}$ & 0 & 0 & 0 & 0 & 0 & 0 & 0 & 0 & 0 \\
sum & 100 & 0 & 100 & 0 & 0 & 100 & 100 & 0 & 100 \\
\hline
\end{tabular}

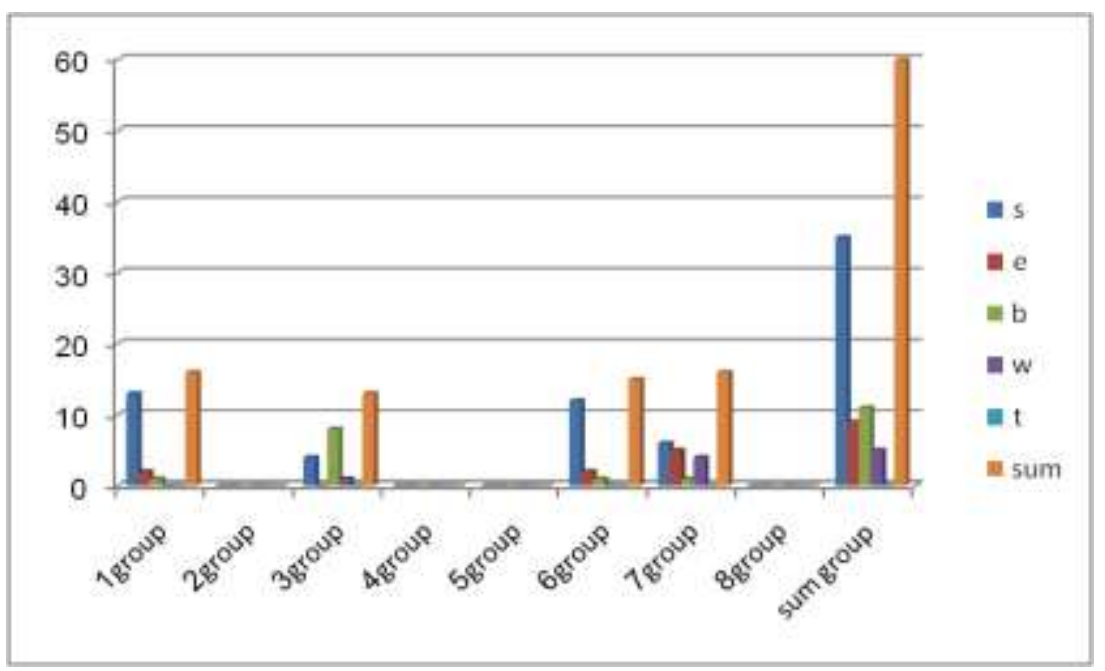




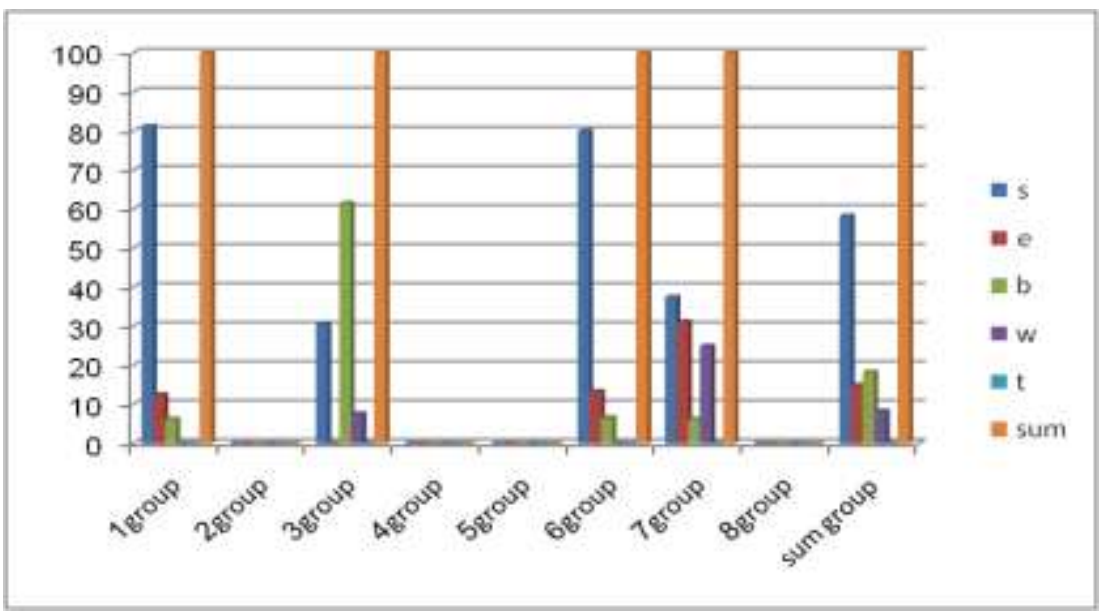

Male:

male

\begin{tabular}{|lllllllllr|}
\hline male group1 group2 group3 group4 group5 & \multicolumn{3}{c|}{ group6 group7 group8 } & \multicolumn{2}{c|}{ sum group } \\
$\mathrm{s}$ & 0 & 9 & 0 & 10 & 9 & 0 & 0 & 10 & 38 \\
$\mathrm{e}$ & 0 & 5 & 0 & 4 & 3 & 0 & 0 & 6 & 18 \\
$\mathrm{~b}$ & 0 & 0 & 0 & 2 & 2 & 0 & 0 & 1 & 5 \\
$\mathrm{~W}$ & 0 & 2 & 0 & 0 & 2 & 0 & 0 & 4 & 8 \\
$\mathrm{t}$ & 0 & 0 & 0 & 0 & 1 & 0 & 0 & 0 & 1 \\
sum & 0 & 16 & 0 & 16 & 17 & 0 & 0 & 21 & 70 \\
\hline
\end{tabular}

percentage of male

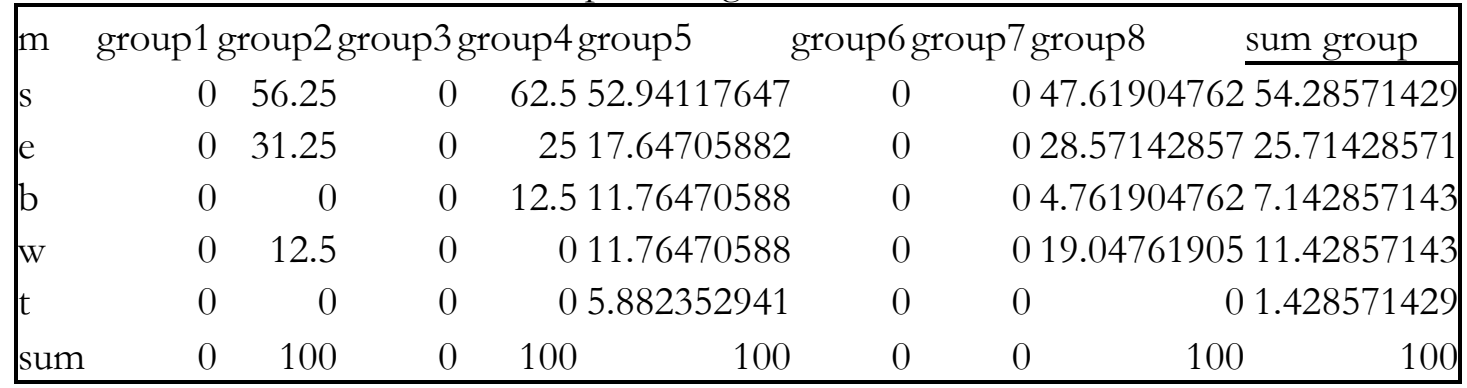

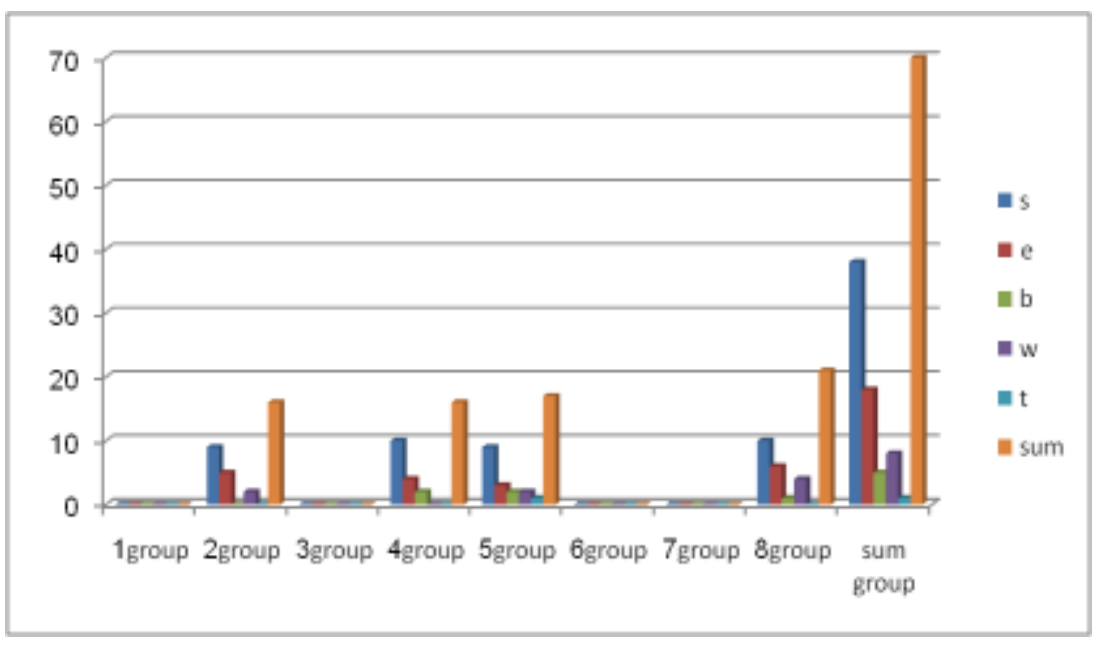


ISSN: 2685-4813 (Online), 2685-4805 (Print)

Vol. 1 , No. 1, July 2019, Page: 33-55

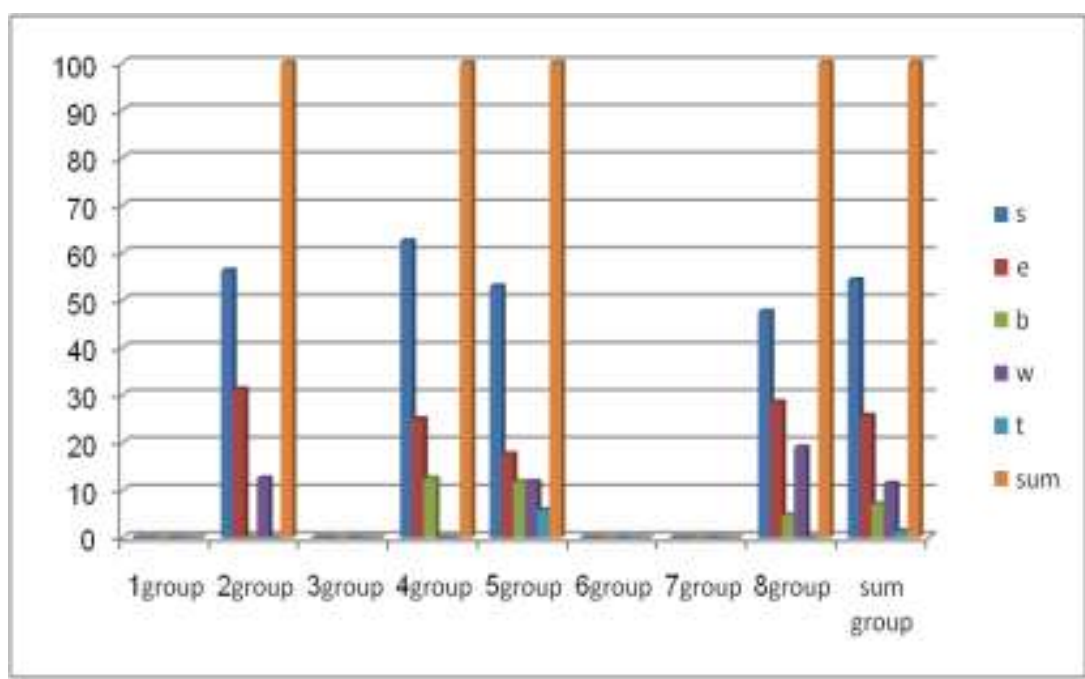

Sum: male \& female

sum male \& female

\begin{tabular}{|lrrrrrrrrr|}
\hline & group1 group2 group3 group4 group5 & \multicolumn{3}{c|}{ group6 group7 group8 } & \multicolumn{2}{c|}{ sum group } \\
$\mathrm{s}$ & 13 & 9 & 4 & 10 & 9 & 12 & 6 & 10 & 73 \\
$\mathrm{e}$ & 2 & 5 & 0 & 4 & 3 & 2 & 5 & 6 & 27 \\
$\mathrm{~b}$ & 1 & 0 & 8 & 2 & 2 & 1 & 1 & 1 & 16 \\
$\mathrm{w}$ & 0 & 2 & 1 & 0 & 2 & 0 & 5 & 4 & 14 \\
$\mathrm{t}$ & 0 & 0 & 0 & 0 & 1 & 0 & 0 & 0 & 1 \\
$\mathrm{sum}$ & 16 & 16 & 13 & 16 & 17 & 15 & 17 & 21 & 131 \\
\hline
\end{tabular}

percentage of sum male \& female

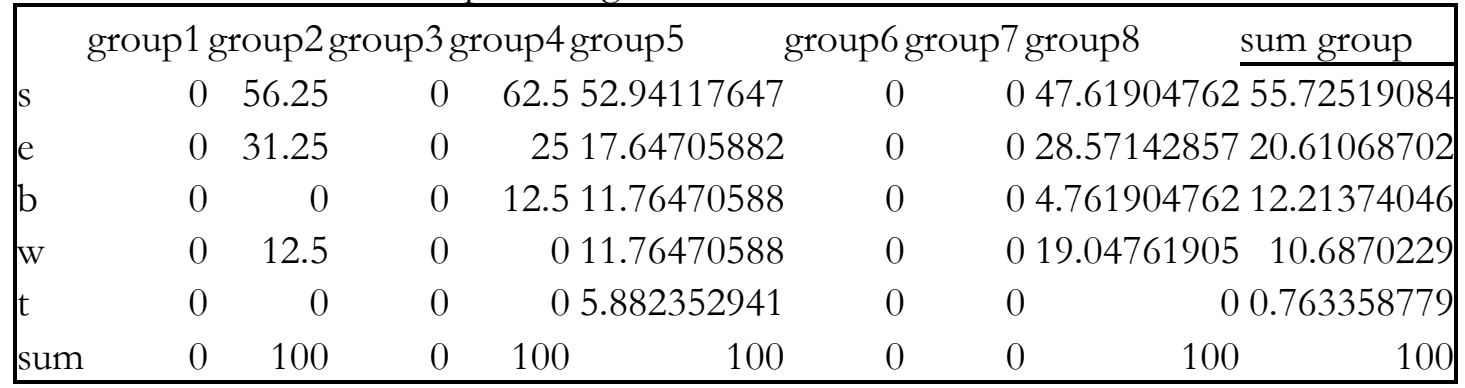

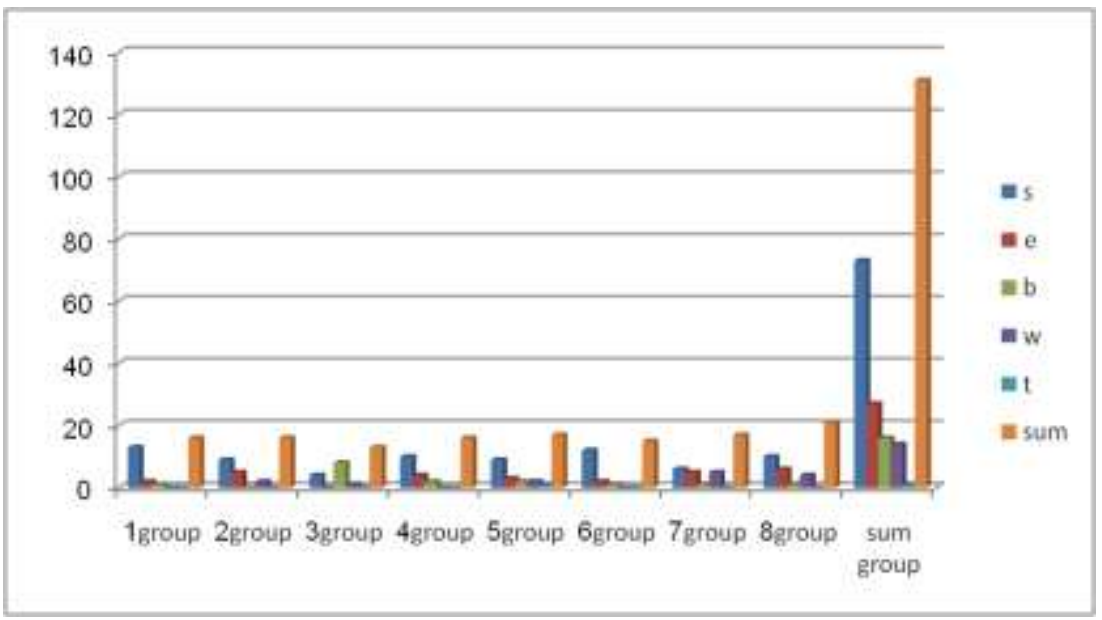




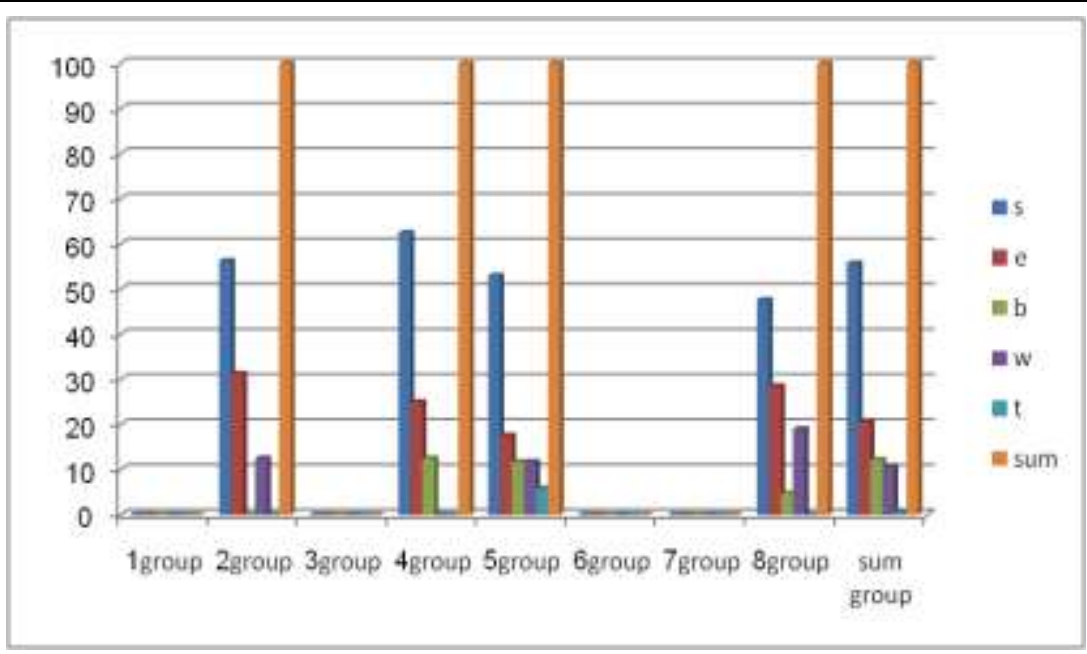

Looking more carefully at table 2 indicates that though a strong tendency was found toward the use of present tense to talk about future, the subjects didn't perform so much like each other. For example the subjects number 1 and 6 use the present tense $81 \%$ and $80 \%$ respectively. However the subjects' number 3 and 7 used the present tense $31 \%$ and $38 \%$ respectively. Searching for the use of future tense, we noticed that 3 of our subjects (number 1,4 and 6) did not use the future verb at all. Among the whole 131 sentences that we extracted, only 13 sentences possessed future verb $(10 \%)$ and $73 \%$ of sentences had present verb $(56 \%)$. In the whole 8 interviews we came across only 1 case of application of present perfect for talking about future.

Now let's investigate the issue from another point of view. Dows the age of people have any effect on their choice of future variability? Do the old people have a special tendency toward structure and the young people for the other ones? Table 3 shows the variations of future structures from the point of view of age.

\section{Table 3: future variation with age}

Young:

future variation with age

\begin{tabular}{|lrlrlllllr|}
\hline Young group1 group2 group3 group4 group5 & \multicolumn{4}{c|}{ group6 group7 group8 sum group } \\
S & 13 & 0 & 4 & 10 & 9 & 0 & 0 & 0 & 36 \\
E & 2 & 0 & 0 & 4 & 3 & 0 & 0 & 0 & 9 \\
B & 1 & 0 & 8 & 2 & 2 & 0 & 0 & 0 & 13 \\
W & 0 & 0 & 1 & 0 & 2 & 0 & 0 & 0 & 3 \\
T & 0 & 0 & 0 & 0 & 1 & 0 & 0 & 0 & 1 \\
Sum & 16 & 0 & 13 & 16 & 17 & 0 & 0 & 0 & 62 \\
\hline
\end{tabular}

percentage of future variation with age

\begin{tabular}{|lrrrrrrrrr|}
\hline \multicolumn{1}{|c}{ Young group1 group2 group3 group4 group5 } & \multicolumn{3}{c|}{ group6 group7 group8 sum group } \\
S & 81.25 & 0 & 30.77 & 62.5 & 52.94117647 & 0 & 0 & 0 & 58.06451613 \\
$\mathrm{E}$ & 12.5 & 0 & 0 & 25 & 17.64705882 & 0 & 0 & 0 & 14.51612903 \\
$\mathrm{~B}$ & 6.25 & 0 & 61.54 & 12.5 & 11.76470588 & 0 & 0 & 0 & 20.96774194 \\
$\mathrm{~W}$ & 0 & 0 & 7.692 & 0 & 11.76470588 & 0 & 0 & 0 & 4.838709677 \\
$\mathrm{~T}$ & 0 & 0 & 0 & 0 & 5.882352941 & 0 & 0 & 0 & 1.612903226 \\
Sum & 100 & 0 & 100 & 100 & 100 & 0 & 0 & 0 & 100 \\
\hline
\end{tabular}


ISSN: 2685-4813 (Online), 2685-4805 (Print)

Vol. 1 , No. 1, July 2019, Page: 33-55
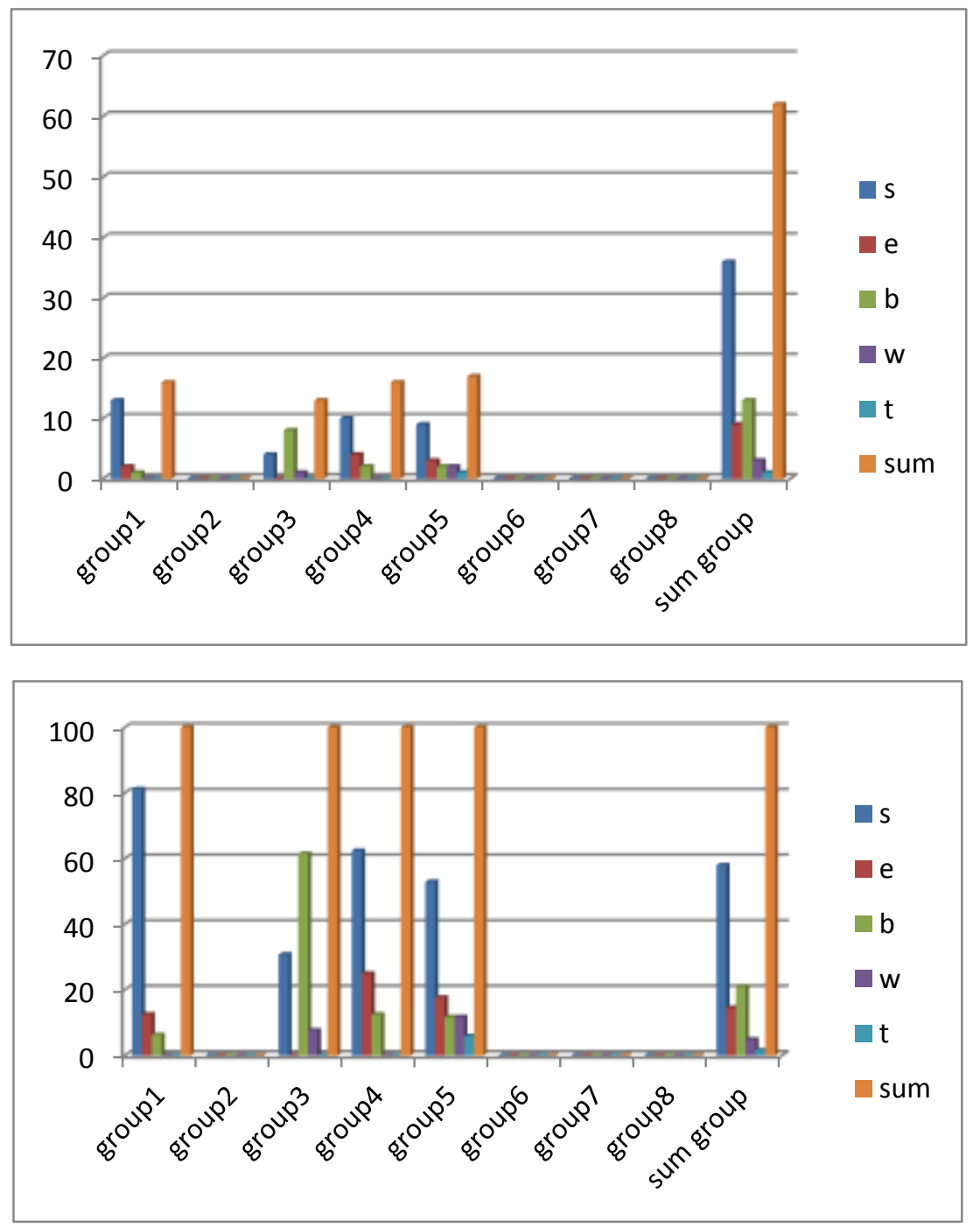

Old:

future variation with age

\begin{tabular}{|llllllrlrr|}
\hline ld & group1 group2 group3 group4 group5 group6 group7 group8 & \multicolumn{2}{c|}{ sum group } \\
$\mathrm{s}$ & 0 & 5 & 0 & 0 & 0 & 12 & 6 & 10 & 33 \\
$\mathrm{e}$ & 0 & 5 & 0 & 0 & 0 & 2 & 5 & 6 & 18 \\
$\mathrm{~b}$ & 0 & 0 & 0 & 0 & 0 & 1 & 1 & 1 & 3 \\
$\mathrm{w}$ & 0 & 2 & 0 & 0 & 0 & 0 & 5 & 4 & 11 \\
$\mathrm{t}$ & 0 & 0 & 0 & 0 & 0 & 0 & 0 & 0 & 0 \\
sum & 0 & 12 & 0 & 0 & 0 & 15 & 17 & 21 & 65 \\
\hline
\end{tabular}

percentage of future variation with age

\begin{tabular}{|lrrrrrrrr|r|}
\hline old & group1 group2 group3 group4 group5 group6 group7 group8 & \multicolumn{2}{c|}{ sum group } \\
s & 0 & 41.67 & 0 & 0 & 0 & 80 & 35.29 & 47.61904762 & 50.76923077 \\
$\mathrm{e}$ & 0 & 41.67 & 0 & 0 & 0 & 13.33 & 29.41 & 28.57142857 & 27.69230769 \\
$\mathrm{~b}$ & 0 & 0 & 0 & 0 & 0 & 6.667 & 5.882 & 4.761904762 & 4.615384615 \\
$\mathrm{~W}$ & 0 & 16.67 & 0 & 0 & 0 & 0 & 29.41 & 19.04761905 & 16.92307692 \\
$\mathrm{t}$ & 0 & 0 & 0 & 0 & 0 & 0 & 0 & 0 & 0 \\
sum & 0 & 100 & 0 & 0 & 0 & 100 & 100 & 100 & 100 \\
\hline
\end{tabular}



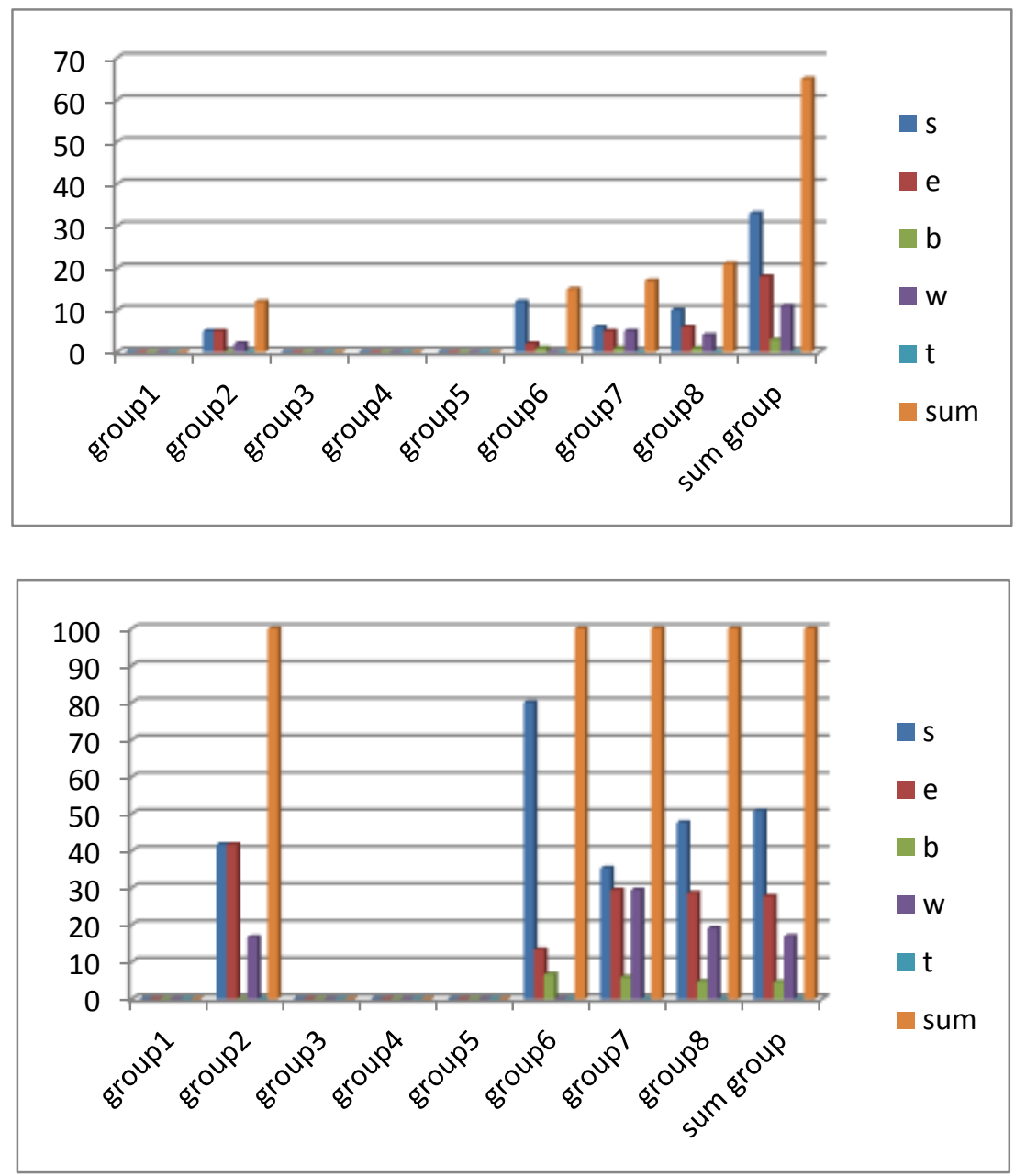

Sum:

sum future variation with age

\begin{tabular}{|lrrrrrrrrr|}
\hline sumgroup1 group2 group3 group4 group5 & \multicolumn{3}{c}{ group6 group7 group8 } & \multicolumn{2}{c|}{ sum group } \\
$\mathrm{s}$ & 13 & 9 & 0 & 10 & 9 & 0 & 0 & 10 & 51 \\
$\mathrm{e}$ & 0 & 5 & 0 & 4 & 3 & 0 & 0 & 6 & 18 \\
$\mathrm{~b}$ & 0 & 0 & 0 & 2 & 2 & 0 & 0 & 1 & 5 \\
$\mathrm{w}$ & 0 & 2 & 10 & 10 & 2 & 0 & 10 & 4 & 38 \\
$\mathrm{t}$ & 0 & 10 & 10 & 0 & 1 & 0 & 0 & 0 & 21 \\
$\mathrm{sum}$ & 13 & 26 & 20 & 26 & 17 & 0 & 10 & 21 & 133 \\
\hline
\end{tabular}

percentage of sum future variation with age

\begin{tabular}{|c|c|c|c|c|c|c|c|}
\hline \multicolumn{5}{|c|}{ sum group1 group2 group3 group4 group5 } & \multicolumn{2}{|c|}{ group6 group 7 group 8} & um group \\
\hline $\mathrm{s}$ & 0 & 34.62 & 0 & 38.4652 .94117647 & 0 & 047.61904762 & 38.34586466 \\
\hline e & 0 & 19.23 & 0 & 15.3817 .64705882 & 0 & 42857 & 13.53383459 \\
\hline $\mathrm{b}$ & 0 & 0 & 0 & 7.69211 .76470588 & 0 & 1904762 & 3.759398496 \\
\hline $\mathrm{w}$ & 0 & 7.692 & 0 & 38.4611 .76470588 & 0 & 019.04761905 & 28.57142857 \\
\hline $\mathrm{t}$ & 0 & 38.46 & 0 & 05.882352941 & 0 & 0 & 15.78947368 \\
\hline sum & 0 & 100 & 0 & 100 & 0 & 100 & \\
\hline
\end{tabular}



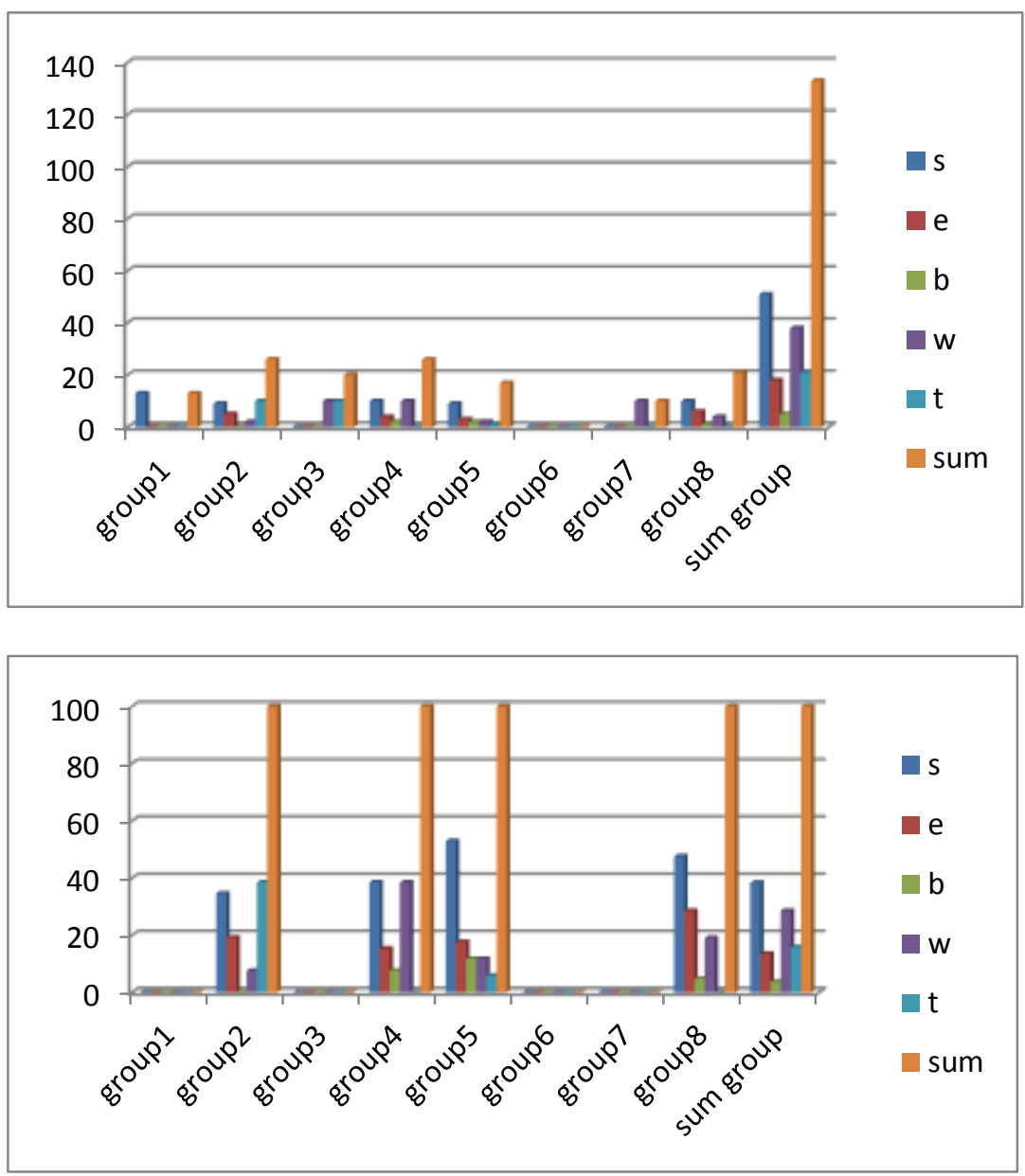

A significant difference between these two groups was not found, but some points are worth considering. Both groups tend to use present verb more than other alternatives. The young group used 36 sentences in present (58\%) and the old group 37 sentences (54\%). But old people tend to use words like "bayad" and "shayad" more than young people $(\mathrm{e}=18)$. In the case of future verb which is somehow the main focus of our study, it is shown that although the overall percentage is not high $(16 \%)$, the old people used the future verb more than young group ( $w=$ $15 \%$ for old group and $w=5 \%$ for the young group).

The next factor that we are going to consider with the future variation is the animacy of subject. It is felt that animate or inanimate subject of sentences influences the selection of the mood of the future tense. Table 4 shows these variations.

Those sentences which had inanimate subjects tend more to use future verb rather than sentences with animate subjects ( $w=7 \%$ for sentences with animate subjects and $w=17 \%$ for sentences with inanimate subject). 
Table 4: future variation with animacy of subject Animate:

future variation with animacy of subject

\begin{tabular}{|c|c|c|c|c|c|c|c|c|c|}
\hline \multicolumn{5}{|c|}{ aimate group 1 group 2 group 3 group 4} & group 5 & group6 & group 7 & group 8 & sum group \\
\hline$s$ & 11 & 7 & 0 & 3 & 7 & 9 & 5 & 5 & 47 \\
\hline e & 2 & 3 & 0 & 3 & 2 & 2 & 4 & 4 & 20 \\
\hline$b$ & 1 & 0 & 8 & 1 & 2 & 1 & 1 & 1 & 15 \\
\hline$w$ & 0 & 2 & 0 & 0 & 1 & 0 & 1 & 2 & 6 \\
\hline$t$ & 0 & 0 & 0 & 0 & 0 & 0 & 0 & 0 & 0 \\
\hline sum & 14 & 12 & 8 & 7 & 12 & 12 & 11 & 12 & 88 \\
\hline
\end{tabular}

\begin{tabular}{|c|c|c|c|c|c|c|c|c|c|}
\hline \multicolumn{5}{|c|}{ aimate group1 group 2 group 3 group 4} & group 5 & group6 & group 7 & group8 & sum group \\
\hline$s$ & 78.57 & 58.33 & 0 & 42.8658 & 3333333 & & 545.45454545 & 41.66666667 & 53.40909091 \\
\hline e & 14.29 & 25 & 0 & 42.8616 & 56666667 & .66666667 & 736.36363636 & 33.33333333 & 22.72727273 \\
\hline$b$ & 7.143 & 0 & 100 & 14.2916 & 566666678 & 33333333 & 39.090909091 & 8.333333333 & 17.04545455 \\
\hline$w$ & 0 & 16.67 & 0 & 08 & 3333333 & & 09.090909091 & 16.66666667 & 6.818181818 \\
\hline$t$ & 0 & 0 & 0 & 0 & 0 & 0 & 0 & 0 & 0 \\
\hline sum & 100 & 100 & 100 & 100 & 100 & 100 & 100 & 100 & 100 \\
\hline
\end{tabular}

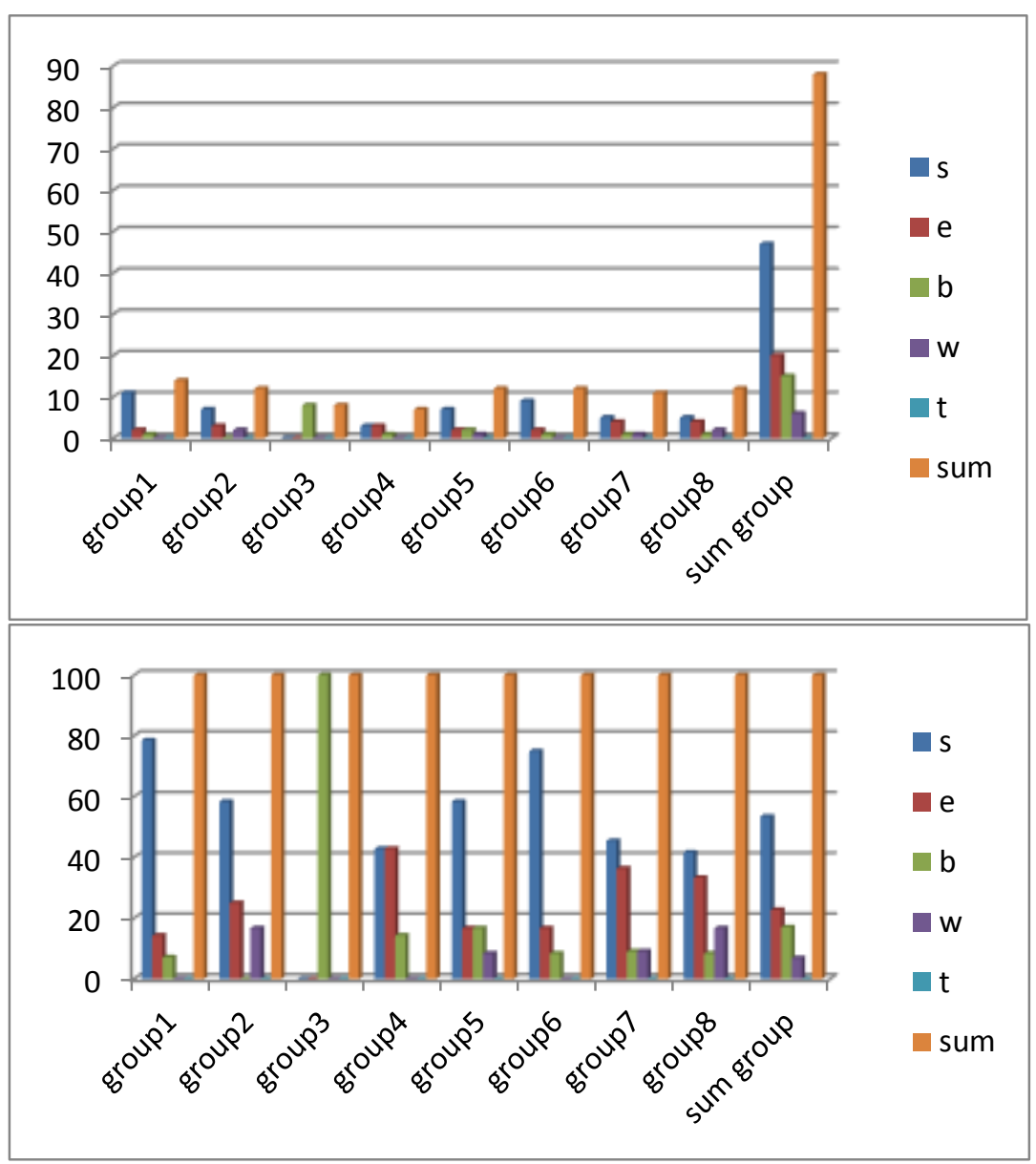


inanimate:

future variation with animacy of subject

\begin{tabular}{|lllllllllr|}
\hline Inanimate group1 group2 group3 group4 group5 group6 group7 group8 & \multicolumn{2}{c|}{ sum group } \\
s & 2 & 2 & 4 & 7 & 2 & 3 & 1 & 5 & 26 \\
e & 0 & 2 & 0 & 1 & 1 & 0 & 1 & 2 & 7 \\
b & 0 & 0 & 0 & 1 & 0 & 0 & 0 & 0 & 1 \\
w & 0 & 0 & 1 & 0 & 1 & 0 & 3 & 2 & 7 \\
t & 0 & 0 & 0 & 0 & 1 & 0 & 0 & 0 & 1 \\
sum & 2 & 4 & 5 & 9 & 5 & 3 & 5 & 9 & 42 \\
\hline
\end{tabular}

percentage of future variation with animacy of subject

\begin{tabular}{|lrrrrrrrrr|}
\hline Inanimate group1 group2 group3 group4 group5 group6 group7 group 8 & \multicolumn{1}{c|}{ sum group } \\
s & 100 & 50 & 80 & 77.78 & 40 & 100 & 20 & 55.55555556 & 61.9047619 \\
e & 0 & 50 & 0 & 11.11 & 20 & 0 & 20 & 22.22222222 & 16.66666667 \\
b & 0 & 0 & 0 & 11.11 & 0 & 0 & 0 & 0 & 2.380952381 \\
w & 0 & 0 & 20 & 0 & 20 & 0 & 60 & 22.22222222 & 16.66666667 \\
$\mathrm{t}$ & 0 & 0 & 0 & 0 & 20 & 0 & 0 & 0 & 2.380952381 \\
sum & 100 & 100 & 100 & 100 & 100 & 100 & 100 & 100 & 100 \\
\hline
\end{tabular}
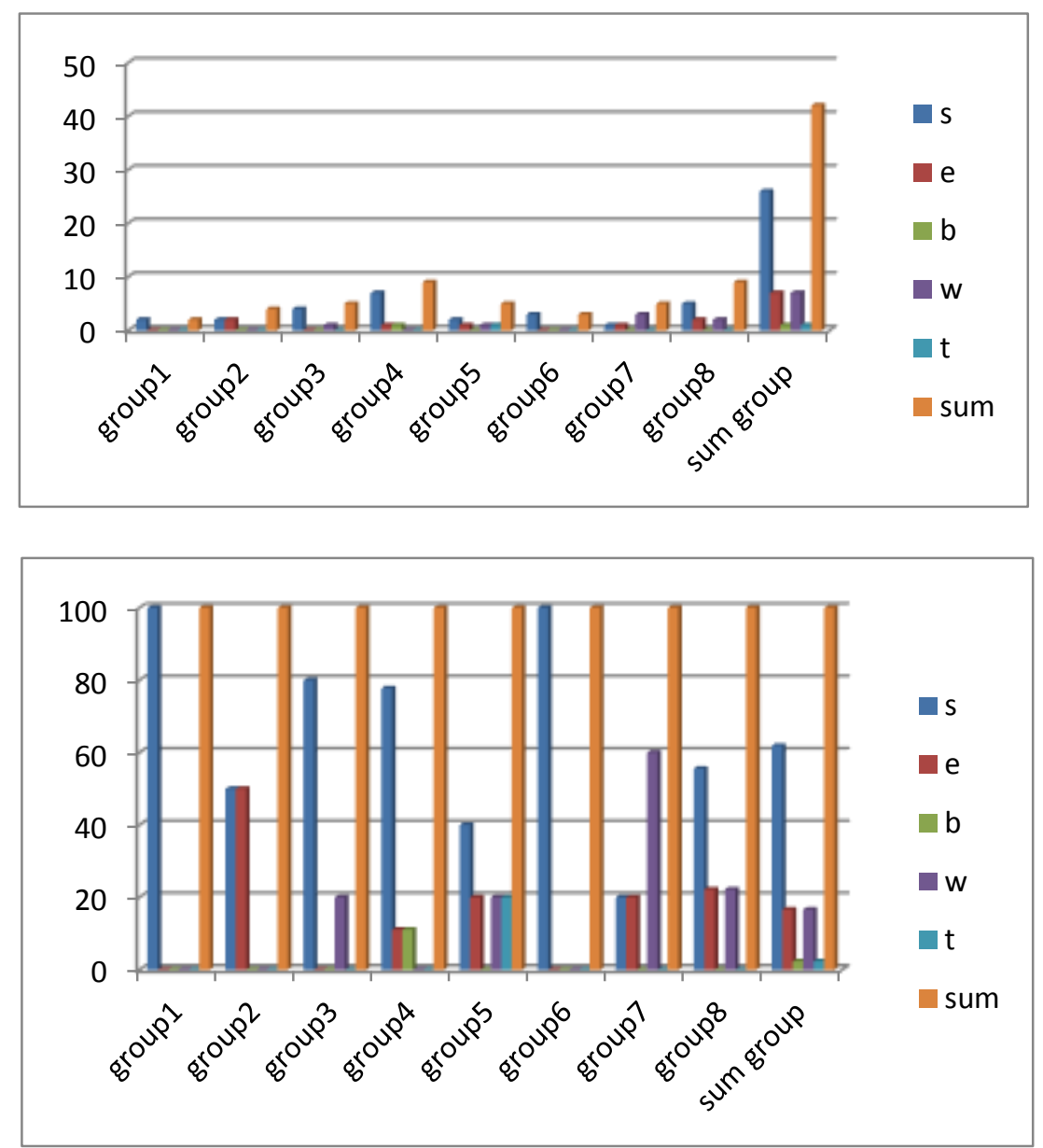
Sum:

future variation with animacy of subject

\begin{tabular}{|c|c|c|c|c|c|c|c|c|c|}
\hline \multicolumn{5}{|c|}{ sumgroup1 group 2 group 3 group 4 group 5} & \multicolumn{3}{|c|}{ group6 group 7 group8 } & \multicolumn{2}{|c|}{ sum group } \\
\hline $\mathrm{s}$ & 13 & 9 & 4 & 10 & 9 & 12 & 6 & 10 & 73 \\
\hline e & 2 & 5 & 0 & 4 & 3 & 2 & 5 & 6 & 27 \\
\hline $\mathrm{b}$ & 1 & 0 & 8 & 2 & 2 & 1 & 1 & 1 & 16 \\
\hline $\mathrm{w}$ & 0 & 2 & 1 & 0 & 2 & 0 & 4 & 4 & 13 \\
\hline t & 0 & 0 & 0 & 0 & 1 & 0 & 0 & 0 & 1 \\
\hline sum & 16 & 16 & 13 & 16 & 17 & 15 & 16 & 21 & 130 \\
\hline
\end{tabular}

percentage of future variation with animacy of subject

\begin{tabular}{|c|c|c|c|c|c|c|c|}
\hline \multicolumn{5}{|c|}{ sum group1 group 2 group 3 group 4 group 5} & \multicolumn{2}{|c|}{ group6 group 7 group 8} & sum group \\
\hline s & 81.25 & 56.25 & 30.77 & 62.552 .94117647 & 80 & 37.547 .61904762 & 56.15384615 \\
\hline e & 12.5 & 31.25 & 0 & 2517.64705882 & 13.33 & 57142857 & 20.76923077 \\
\hline $\mathrm{b}$ & 6.25 & 0 & 61.54 & 12.511 .76470588 & 6.667 & 6.254 .761904762 & 12.30769231 \\
\hline $\mathrm{w}$ & 0 & 12.5 & 7.692 & 011.76470588 & 0 & 2519.04761905 & 10 \\
\hline$\pi^{2}$ & 0 & 0 & 0 & 05.882352941 & 0 & 0 & 0.769230769 \\
\hline sum & 100 & 100 & 100 & 100 & 100 & 100 & 100 \\
\hline
\end{tabular}
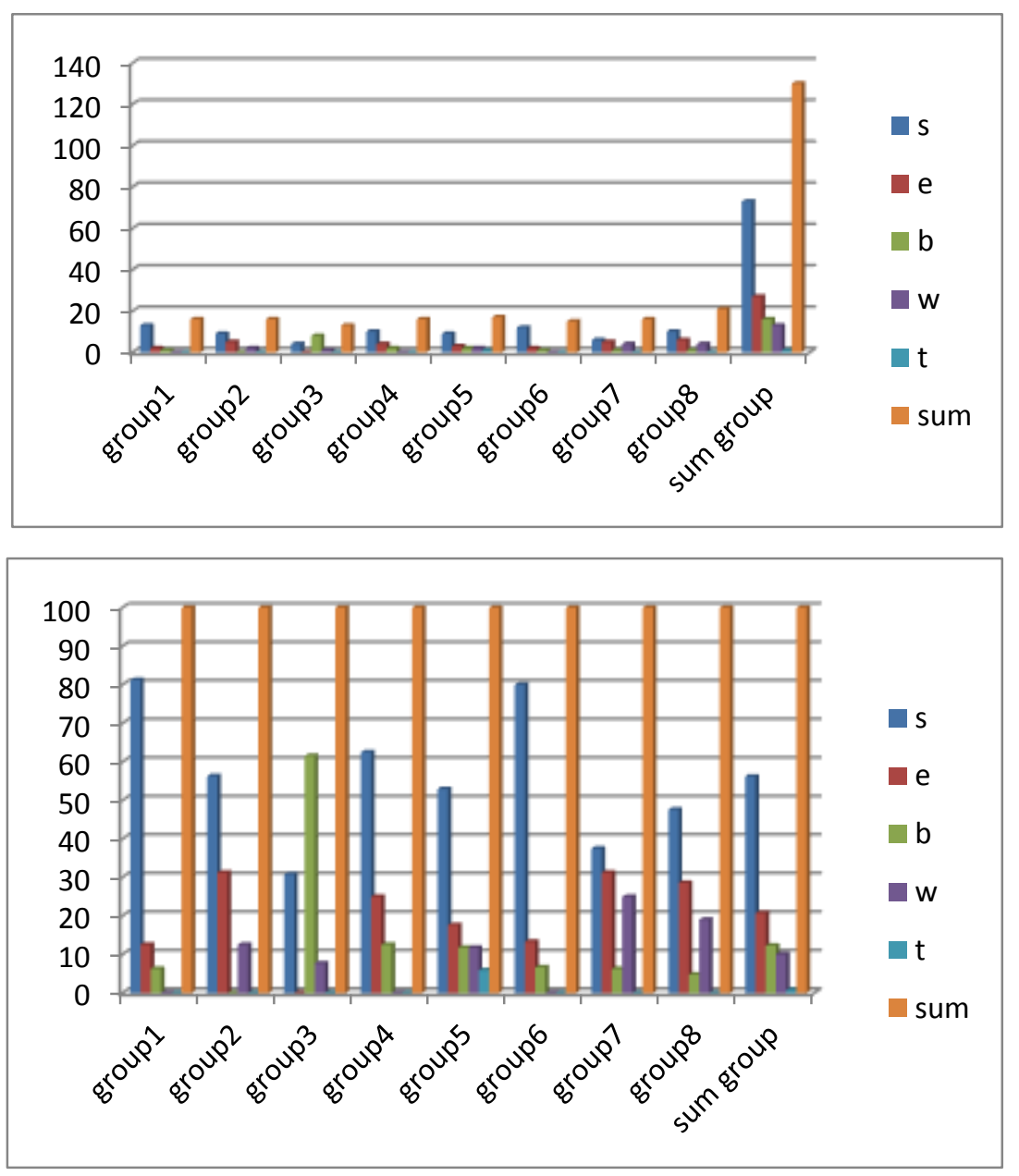
We felt that interviewers may affect the subject's choice of words and tenses. One interview may conduct the interview in a very naturalistic and informal manner; the other one may not be skillful enough and direct the interview very formally. Therefore we took the interviewers as a factor group (codes "c" and "d"). Table 5 shows the interviews which are arranged by the interviewers. The first five subjects were interviewed by the first interviewer and the last three ones with the second interviewer.

Investigating and scrutinizing table $5 \mathrm{~T}$ we come to this conclusion that the interviewers did not have very significant role in the results of the study. The percentage of each variation for the two interviewers are not so different. But we see that the second interviewers has elicited more future verb rather than the first interviewer. ( $\mathrm{w}=6 \%$ for the first interviewer and $\mathrm{w}=15 \%$ for the second interviewer). Among the whole 78 sentences which are extracted from the interviews of the first interviewer just five sentences possessed future verb and in the case of the second interviewer, the whole number of sentences extracted is 52 and 8 sentences had future verb. These differences may also be accounted for by other factors of subjects which are not simply attributable to interviewers.

\section{Table5: future variation with interviewers}

First:

future variation with interviewers

\begin{tabular}{|lcrrrrrrrr|r|}
\hline first interviewer & group1 group2 group3 group4 group5 & \multicolumn{3}{c|}{ group6 group 7 group8 } & sum group \\
s & 13 & 9 & 4 & 10 & 9 & 0 & 0 & 0 & 45 \\
e & 2 & 5 & 0 & 4 & 3 & 0 & 0 & 0 & 14 \\
b & 1 & 0 & 8 & 2 & 2 & 0 & 0 & 0 & 13 \\
w & 0 & 2 & 1 & 0 & 2 & 0 & 0 & 0 & 5 \\
t & 0 & 0 & 0 & 0 & 1 & 0 & 0 & 0 & 1 \\
sum & 16 & 16 & 13 & 16 & 17 & 0 & 0 & 0 & 78 \\
\hline
\end{tabular}

percentage of future variation with interviewers

\begin{tabular}{|c|c|c|c|c|c|c|}
\hline \multicolumn{5}{|c|}{ sum first interviewer group1 group 2 group 3 group 4 group 5} & \multicolumn{2}{|c|}{ group6 group 7 group8 sum group } \\
\hline s & 81.25 & 56.25 & 30.77 & 62.552 .94117647 & 0 & 0 \#DIV $/ 0 ! 57.69230769$ \\
\hline e & 12.5 & 31.25 & 0 & 2517.64705882 & 0 & 0 \#DIV $/ 0 ! 17.94871795$ \\
\hline $\mathrm{b}$ & 6.25 & 0 & 61.54 & 12.511 .76470588 & 0 & 0 \#DIV/0! 16.66666667 \\
\hline w & 0 & 12.5 & 7.692 & 011.76470588 & 0 & 0\#DIV $/ 0 ! \quad 6.41025641$ \\
\hline$t$ & 0 & 0 & 0 & 05.882352941 & 0 & 0 \#DIV/0! 1.282051282 \\
\hline sum & 100 & 100 & 100 & 100 & 0 & $0 \#$ DIV $/ 0$ ! \\
\hline
\end{tabular}

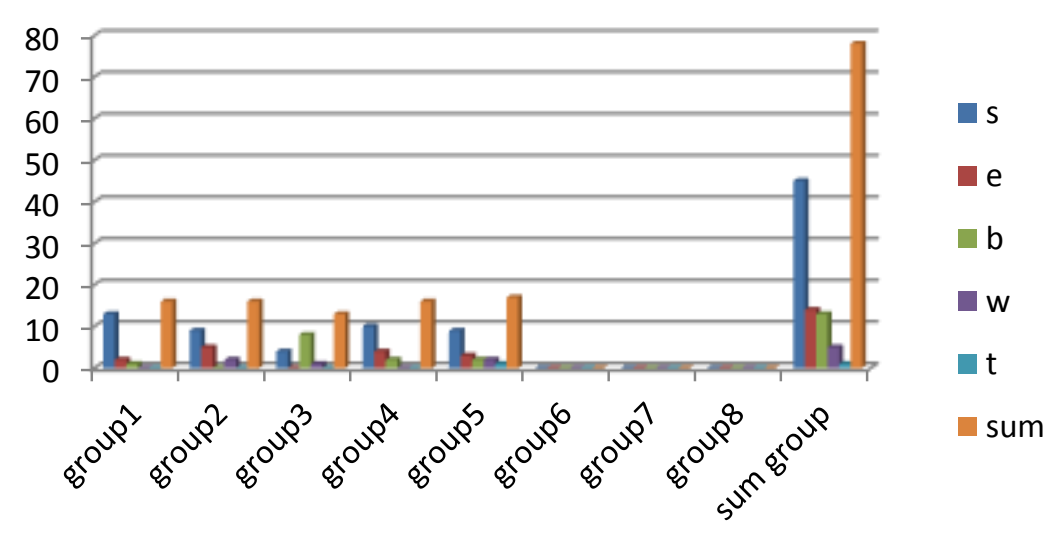




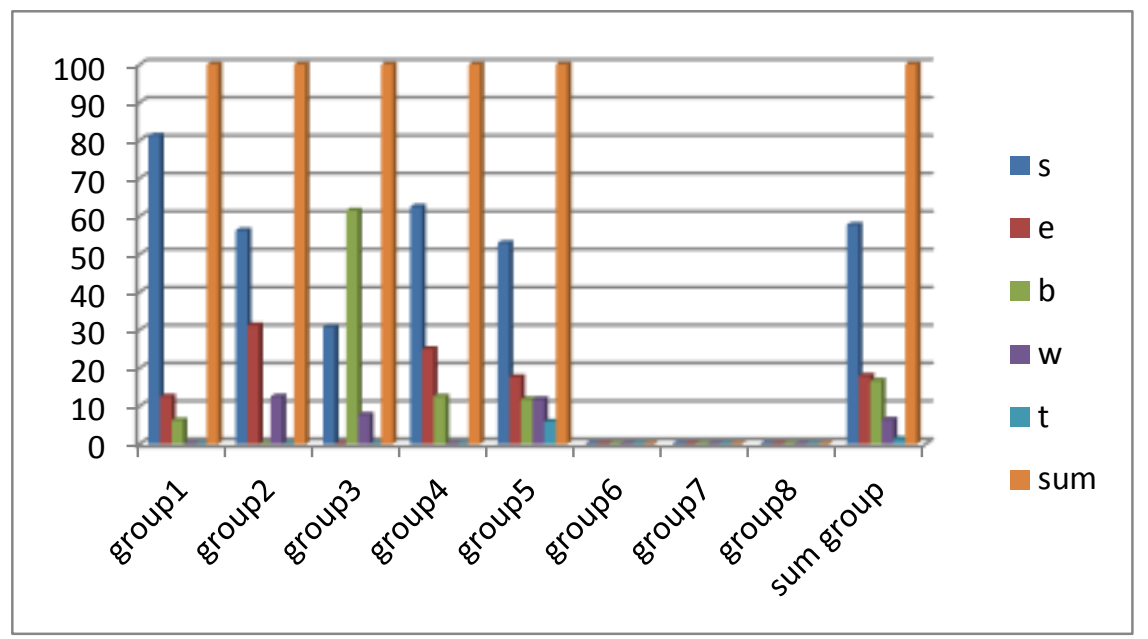

Second:

future variation with interviewers

\begin{tabular}{|lccccccccc|}
\hline second interviewer & group1 group2 group3 group4 group5 group6 group 7 group8 & \multicolumn{2}{c|}{ sum group } \\
s & 0 & 0 & 0 & 0 & 0 & 12 & 6 & 10 & 28 \\
e & 0 & 0 & 0 & 0 & 0 & 2 & 5 & 6 & 13 \\
b & 0 & 0 & 0 & 0 & 0 & 1 & 1 & 1 & 3 \\
W & 0 & 0 & 0 & 0 & 0 & 0 & 4 & 4 & 8 \\
t & 0 & 0 & 0 & 0 & 0 & 0 & 0 & 0 & 0 \\
sum & 0 & 0 & 0 & 0 & 0 & 15 & 16 & 21 & 52 \\
\hline
\end{tabular}

percentage of future variation with interviewers

\begin{tabular}{|lclllllrrrr|}
\hline second interviewer & group1 group2 group3 group4 group5 group6 group 7 group8 & \multicolumn{2}{c|}{ sum group } \\
s & 0 & 0 & 0 & 0 & 0 & 80 & 37.5 & 47.61904762 & 53.84615385 \\
e & 0 & 0 & 0 & 0 & 0 & 13.33 & 31.25 & 28.57142857 & 25 \\
b & 0 & 0 & 0 & 0 & 0 & 6.667 & 6.25 & 4.761904762 & 5.769230769 \\
w & 0 & 0 & 0 & 0 & 0 & 0 & 25 & 19.04761905 & 15.38461538 \\
$\mathrm{t}$ & 0 & 0 & 0 & 0 & 0 & 0 & 0 & 0 & 0 \\
sum & 0 & 0 & 0 & 0 & 0 & 100 & 100 & 100 & 100 \\
\hline
\end{tabular}

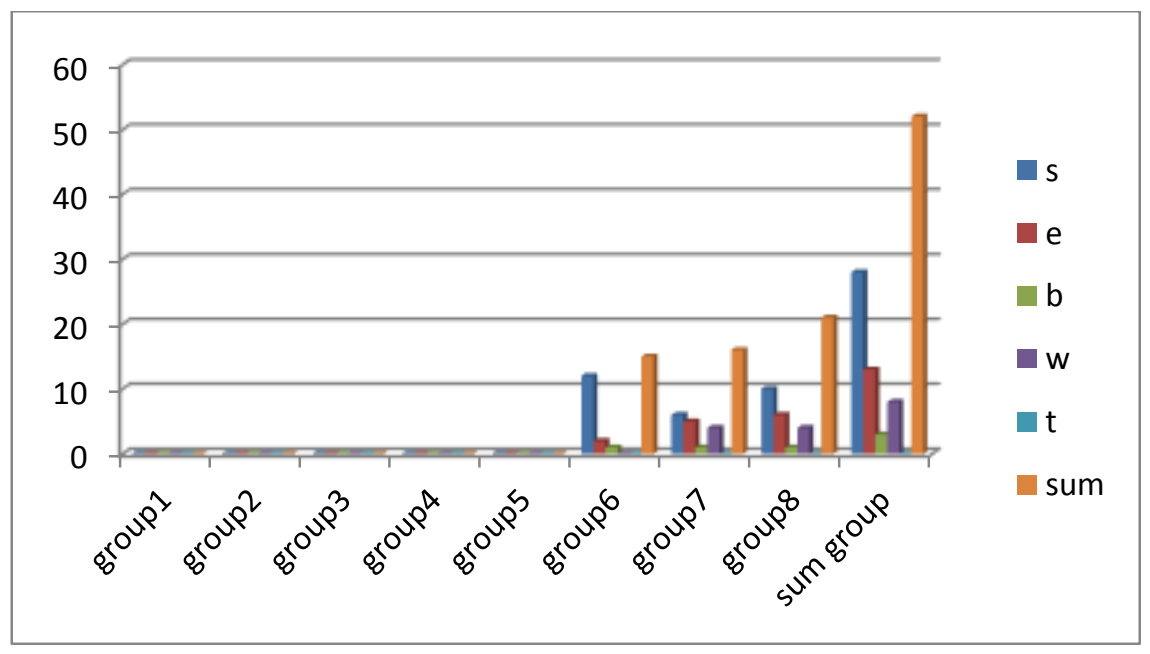




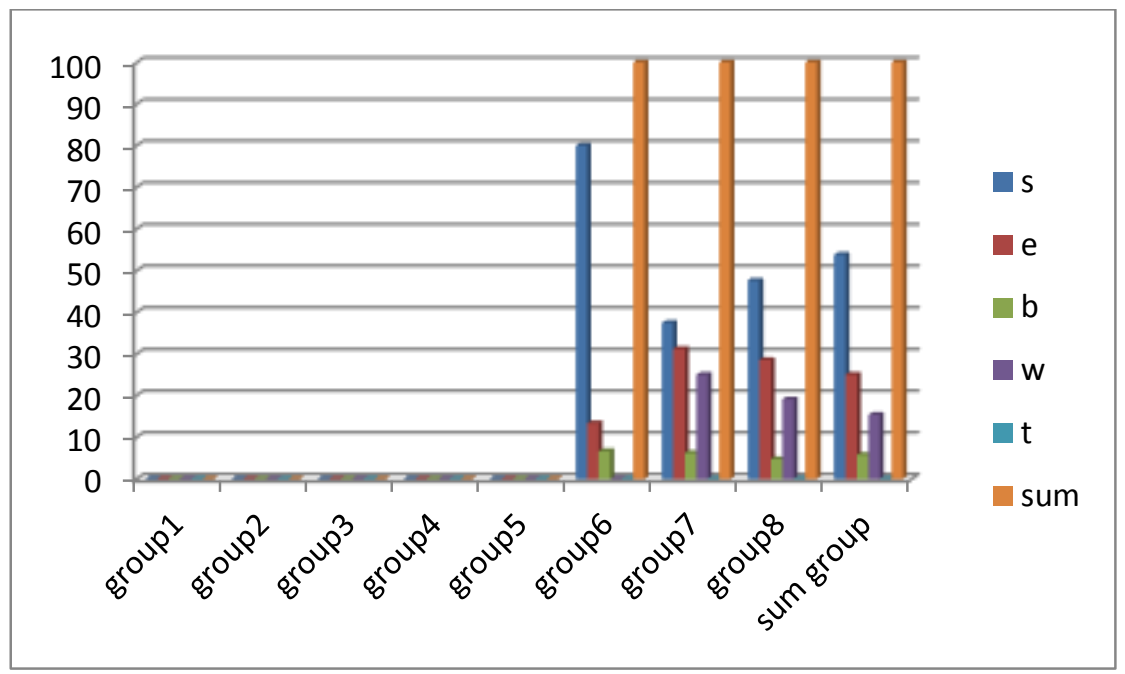

Sum:

future variation with interviewers

\begin{tabular}{|lrrrrrrrrr|}
\hline \multicolumn{3}{l}{ sumgroup1 group2 group3 group4 group5 } & \multicolumn{3}{c|}{ group6 group7 group8 } & \multicolumn{2}{c|}{ sum group } \\
s & 13 & 9 & 4 & 10 & 9 & 12 & 6 & 10 & 73 \\
$\mathrm{e}$ & 2 & 5 & 0 & 4 & 3 & 2 & 5 & 6 & 27 \\
$\mathrm{~b}$ & 1 & 0 & 8 & 2 & 2 & 1 & 1 & 1 & 16 \\
$\mathrm{w}$ & 0 & 2 & 1 & 0 & 2 & 0 & 4 & 4 & 13 \\
$\mathrm{t}$ & 0 & 0 & 0 & 0 & 1 & 0 & 0 & 0 & 1 \\
sum & 16 & 16 & 13 & 16 & 17 & 15 & 16 & 21 & 130 \\
\hline
\end{tabular}

percentage of future variation with interviewers

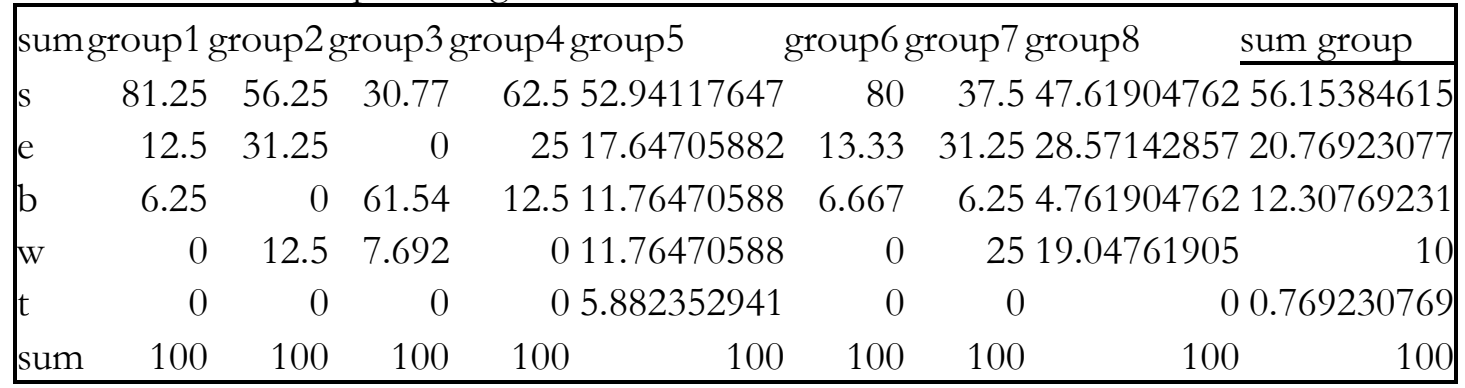

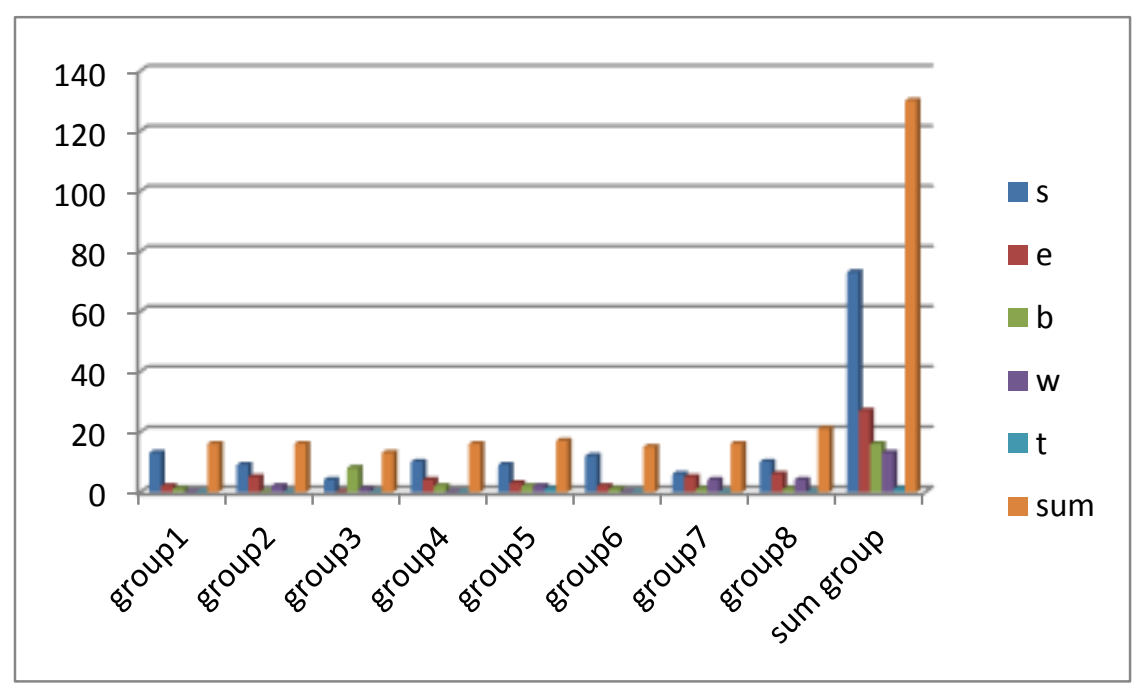




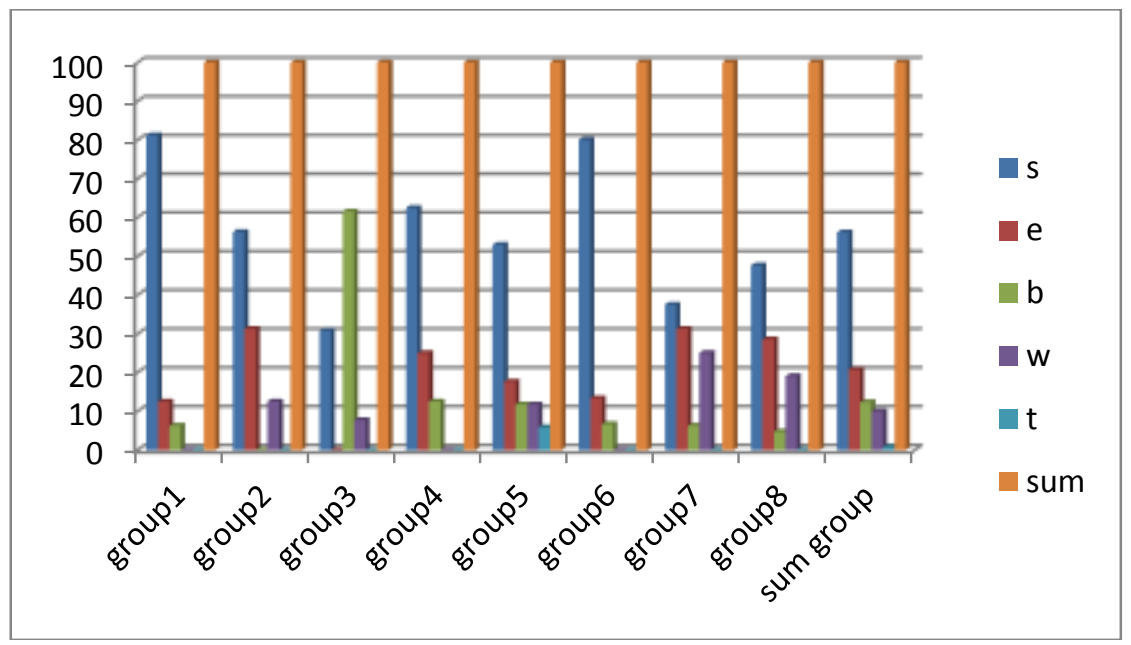

The last factor that we are going to investigate along with future variability is the absence or presence of temporal adverbials in the sentences used ( + shows the presence of adverb and show the absence of that). Table 6 summarized the data gathered from our subjects based on this factor.

The significant difference that stands our regarding the absence or presence of adverb of is that among the sentences which lack the adverb, none of them are made with words like "bayad" and "shayad" (b=0). But the same case for the sentences with temporal adverbial is 16 sentences $(b=14 \%)$. Among the 130 sentences which are extracted only 16 sentences had temporal adverbial. The use of future verb is not so different $(\mathrm{w}=12 \%$ for sentences with adverbs and $\mathrm{w}=10 \%$ for sentences without adverb).

Table6: Future Variation with absence or presence of temporal adverb Absence:

Future variation with absence or presence of temporal adverb

\begin{tabular}{|lrrrrrrrrr|}
\hline \multicolumn{2}{l}{ absence group1 group2 group3 group4 } & group5 & \multicolumn{3}{c|}{ group6 group7 } & group8 & sum group \\
s & 9 & 8 & 4 & 8 & 7 & 12 & 4 & 10 & 62 \\
$\mathrm{e}$ & 2 & 3 & 0 & 4 & 3 & 2 & 4 & 6 & 24 \\
$\mathrm{~b}$ & 1 & 0 & 8 & 2 & 2 & 1 & 1 & 1 & 16 \\
$\mathrm{w}$ & 0 & 2 & 1 & 0 & 2 & 0 & 4 & 2 & 11 \\
$\mathrm{t}$ & 0 & 0 & 0 & 0 & 1 & 0 & 0 & 0 & 1 \\
sum & 12 & 13 & 13 & 14 & 15 & 15 & 13 & 19 & 114 \\
\hline
\end{tabular}

percentage of Future variation with absence or presence of temporal adverb

\begin{tabular}{|lrrrrrrrrr|}
\hline \multicolumn{2}{|c|}{ absence group1 group2 group3 group4 } & group5 & group6 group7 & group8 & sum group \\
& 75 & 61.54 & 30.77 & 57.14 & 46.66666667 & 80 & 30.77 & 52.63157895 & 54.38596491 \\
$\mathrm{e}$ & 16.67 & 23.08 & 0 & 28.57 & 20 & 13.33 & 30.77 & 31.57894737 & 21.05263158 \\
$\mathrm{~b}$ & 8.333 & 0 & 61.54 & 14.29 & 13.33333333 & 6.667 & 7.692 & 5.263157895 & 14.03508772 \\
$\mathrm{w}$ & 0 & 15.38 & 7.692 & 0 & 13.33333333 & 0 & 30.77 & 10.52631579 & 9.649122807 \\
$\mathrm{t}$ & 0 & 0 & 0 & 0 & 6.666666667 & 0 & 0 & 0.877192982 \\
sum & 100 & 100 & 100 & 100 & 100 & 100 & 100 & 100 & 100 \\
\hline
\end{tabular}



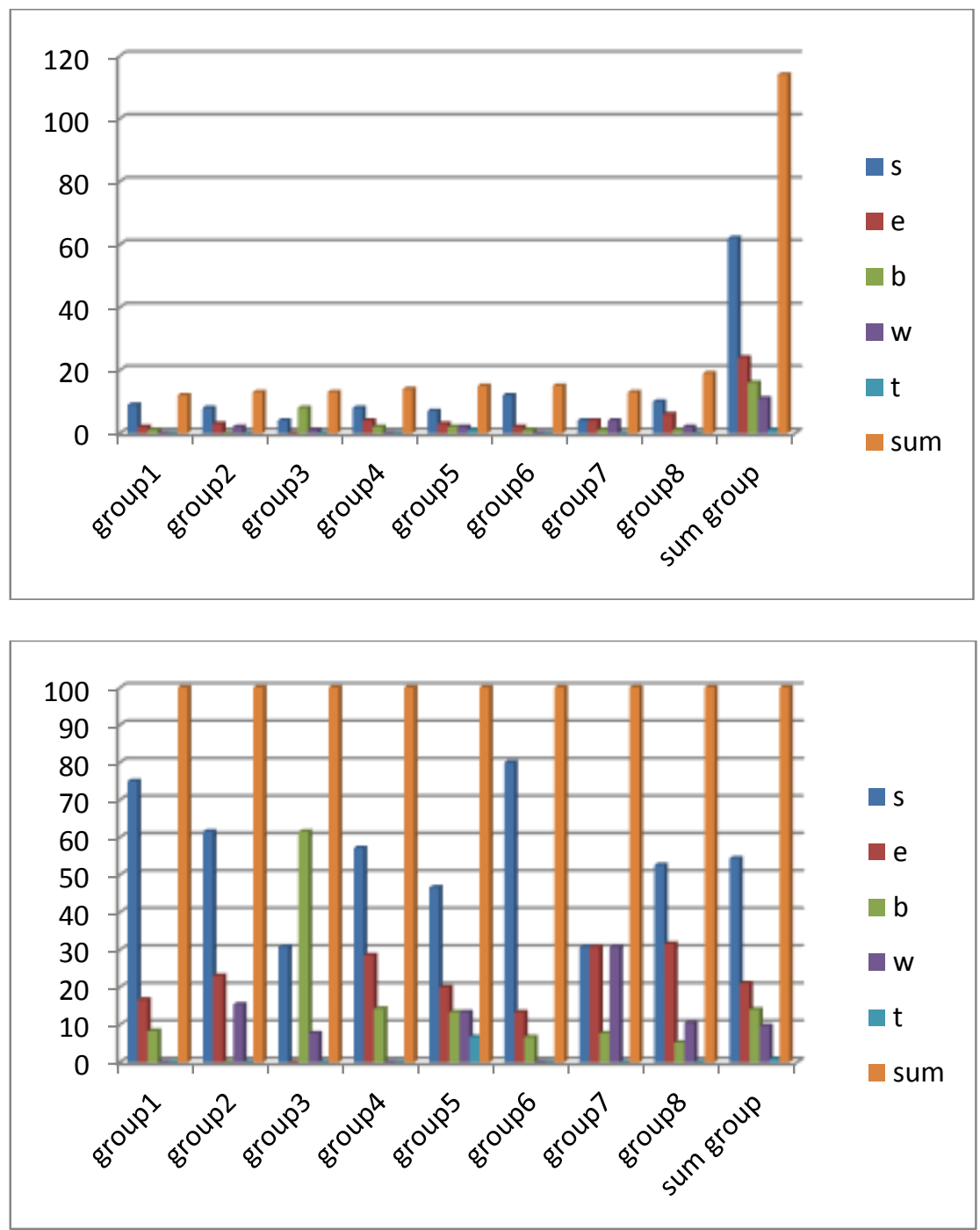

\section{Presence:}

Future variation with absence or presence of temporal adverb

\begin{tabular}{|lrrrrrrrrr|r}
\hline presence & group1 & group2 & group3 & group4 & group5 & group 6 & group7 & group8 & sum group \\
s & 4 & 1 & 0 & 2 & 2 & 0 & 2 & 0 & 11 \\
e & 0 & 2 & 0 & 0 & 0 & 0 & 1 & 0 & 3 \\
b & 0 & 0 & 0 & 0 & 0 & 0 & 0 & 0 & 0 \\
w & 0 & 0 & 0 & 0 & 0 & 0 & 0 & 0 & 0 \\
t & 0 & 0 & 0 & 0 & 0 & 0 & 0 & 0 & 0 \\
sum & 4 & 3 & 0 & 2 & 2 & 0 & 3 & 0 & 14 \\
\hline
\end{tabular}

percentage of Future variation with absence or presence of temporal adverb

\begin{tabular}{|lrrrrrrrrr|r|}
\hline presence & group1 & group2 & group3 & group4 & group5 & group6 & group7 & group8 & \multicolumn{2}{c|}{ sum group } \\
& 100 & 33.33 & 0 & 100 & 100 & 0 & 66.67 & 0 & 78.57142857 \\
s & 0 & 66.67 & 0 & 0 & 0 & 0 & 33.33 & 0 & 21.42857143 \\
b & 0 & 0 & 0 & 0 & 0 & 0 & 0 & 0 & 0 \\
w & 0 & 0 & 0 & 0 & 0 & 0 & 0 & 0 & 0 \\
t & 0 & 0 & 0 & 0 & 0 & 0 & 0 & 0 & 0 \\
sum & 100 & 100 & 0 & 100 & 100 & 0 & 100 & 0 & 100 \\
\hline
\end{tabular}



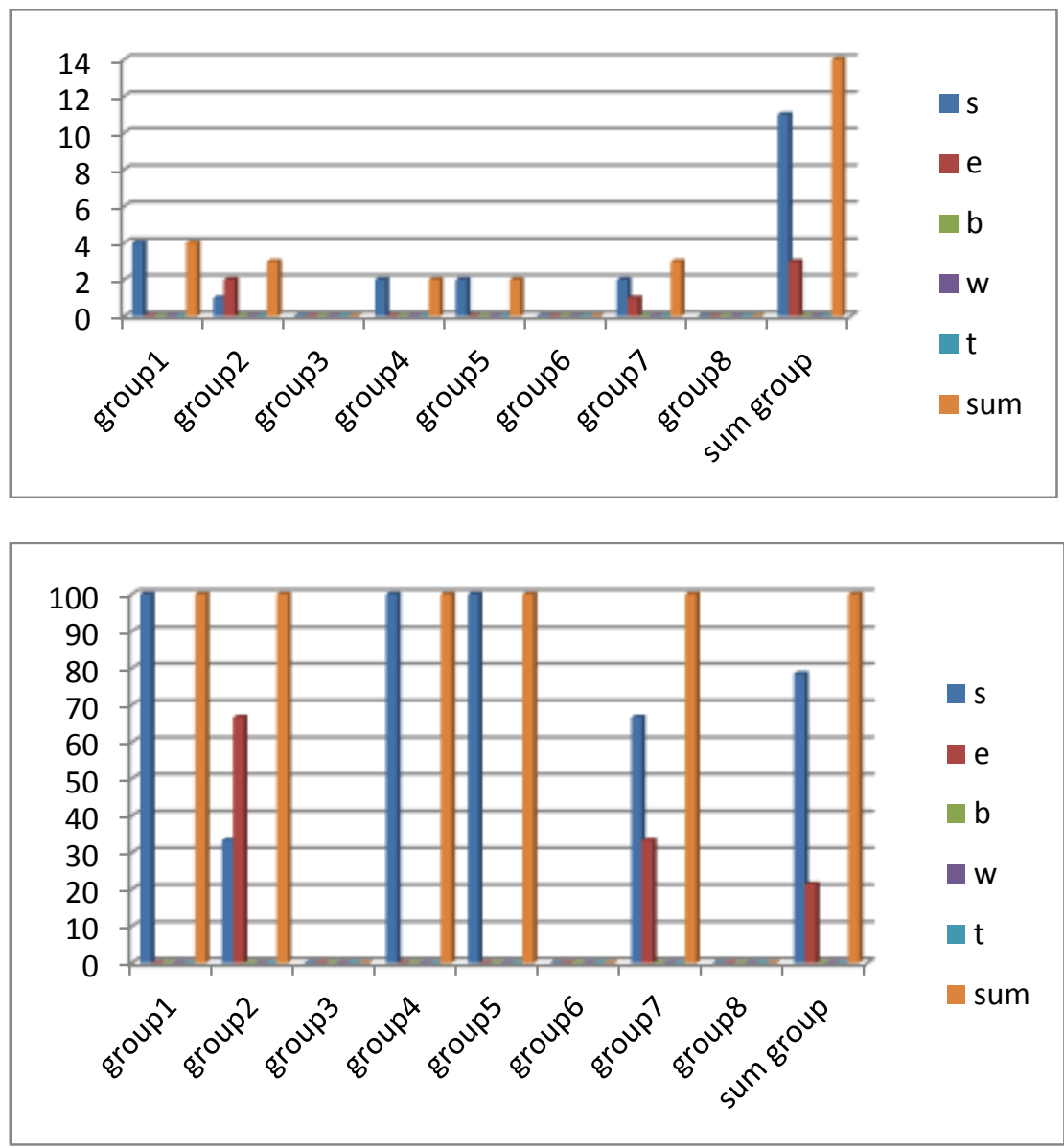

Sum:

Future variation with absence or presence of temporal adverb

\begin{tabular}{|lrrrrrrrrr|}
\hline \multicolumn{3}{c}{ sumgroup1 group2 group3 group4 group5 } & \multicolumn{3}{c|}{ group6 group7 group8 } & \multicolumn{2}{c|}{ sum group } \\
$\mathrm{s}$ & 13 & 9 & 4 & 10 & 9 & 12 & 6 & 10 & 73 \\
$\mathrm{e}$ & 2 & 5 & 0 & 4 & 3 & 2 & 5 & 6 & 27 \\
$\mathrm{~b}$ & 1 & 0 & 8 & 2 & 2 & 1 & 1 & 1 & 16 \\
$\mathrm{w}$ & 0 & 2 & 1 & 0 & 2 & 0 & 4 & 4 & 13 \\
$\mathrm{t}$ & 0 & 0 & 0 & 0 & 1 & 0 & 0 & 0 & 1 \\
sum & 16 & 16 & 13 & 16 & 17 & 15 & 16 & 21 & 130 \\
\hline
\end{tabular}

percentage of Future variation with absence or presence of temporal adverb

\begin{tabular}{|c|c|c|c|c|c|c|c|}
\hline \multicolumn{5}{|c|}{ sumgroup1 group2 group3 group4 group 5} & \multicolumn{2}{|c|}{ group6 group 7 group8 } & sum group \\
\hline s & 81.25 & 56.25 & 30.77 & 62.552 .94117647 & 80 & 37.547 .6190476 & $2 \overline{56.1}$ \\
\hline e & 12.5 & 31.25 & 0 & 2517.64705882 & 13.33 & & 307 \\
\hline $\mathrm{b}$ & 6.25 & 0 & 61.54 & 70588 & 6.667 & 6.254 & 212.30769231 \\
\hline $\mathrm{w}$ & 0 & 12.5 & 7.692 & 011.76470588 & 0 & 2519.0476190 & \\
\hline & 0 & 0 & 0 & 05.882352941 & 0 & 0 & 00.769230769 \\
\hline sum & 100 & 100 & 100 & 100 & 100 & 100 & \\
\hline
\end{tabular}



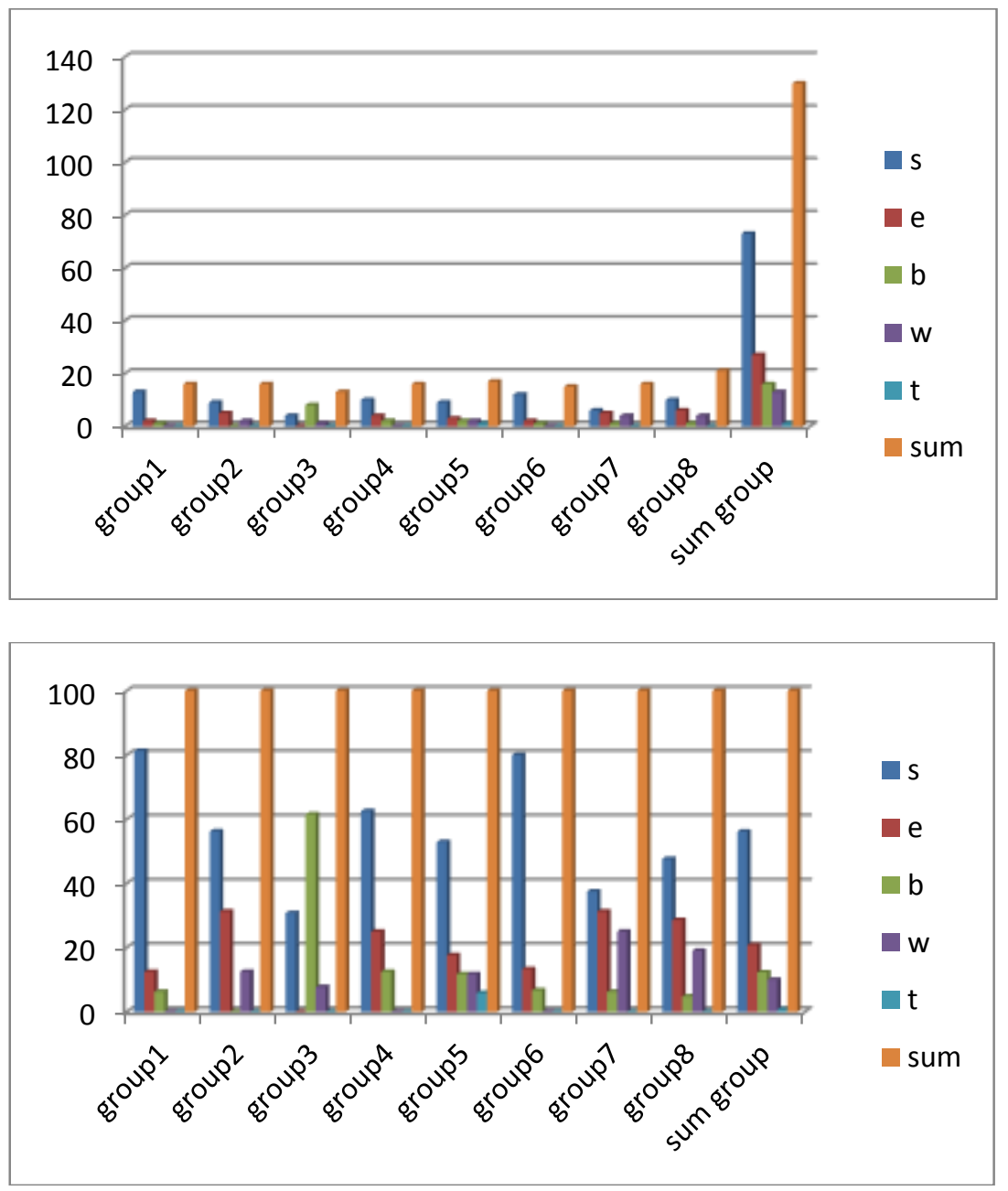

\section{Conclusion}

In conclusion we want to restate that future time is difficult to perceive and describe and for expressing a future activity and the notion of futurity we many choices at our disposal. In the case of Farsi or Persian we can conclude that although future verb has its own structure and definition, it is not applied most of the time in the speaking of Tehrani speakers of Farsi. Present tense is the variation which is proved to be used for the majority of cases to talk about future.

\section{References}

Van der Geer, J., Hanraads, J. A. J., \& Lupton R. A. (2000). The art of writing a scientific article. Journal of Scientific Communications, 163, 51-59

Eichman, p ,(2003). "observation on futurity".

Freduenthal, D ,(2001). "Simulating the temporal reference of Dutch and English".

Lin, J, 2001. "Selectional restrictions of tenses and temporal reference of Chinese bare sentences". Lingua, 113, 271-302.

Lotfi, A.H,(1997). “Tense, IP and parametric Variation”. Proceeding of conference on Language, Cognition, and Interpretation.

Lyons, C.G,(2002). "A look into the Spanish future". University college London, linguistic section and School of communication studies, N. Ireland Polytechnic, UK. 
Sarkar, A,(2000). "The conflict between future tense and modality: the case of will in English". Dep. Of computer and information science, university of Pennsylvania.

Schwarze, C, (2001). "Do sentences have tenses?". The International LFG conference, Hong Kong, June 25-27.

Scriven, M,2001. "Evaluation: Future tense".

Taghva, M. ,Beckly, R.,\& Sadeh, M,(2003). "A stemming algorithm for the Farsi Language”. Information Science Institute, University of Nevada, Las Vegas.

Tomic, O.M,(2003). “The syntax of Balkan Slavic future tenses". Lingua, 114, 517-542.

Walker, J.A; poplak, Sh. , Cacoullos, P.T,(2004). "Looking into the future in English and French". Sociolinguistic Symposium 15, University of Newcastle- Upon- Tyne. 